UNIVERSIDADE DE BRASÍLIA

FACULDADE DE EDUCAÇÃO FÍSICA

PROGRAMA DE PÓS-GRADUAÇÃO STRICTO-SENSU EM EDUCAÇÃO FÍSICA

\title{
DISTRIBUIÇÃO DA PRESSÃO PLANTAR DURANTE O ANDAR E O CORRER EM CRIANÇAS
}

\author{
Paula Ribeiro Mesquita
}

BRASÍLIA

2015 


\title{
DISTRIBUIÇÃO DA PRESSÃO PLANTAR DURANTE O ANDAR E O CORRER EM CRIANÇAS
}

\author{
Paula Ribeiro Mesquita
}

Dissertação apresentada à

Faculdade de Educação Física da Universidade de Brasília, como requisito parcial para obtenção do grau de Mestre em Educação Física 
DEDICATÓRIA

Dedico este trabalho a todos aqueles que me acompanharam e motivaram durante todo o processo. 


\section{AGRADECIMENTOS}

Aos meus pais e ao Vladi, que são os melhores exemplos que eu poderia ter, só tenho a agradecer por todas as oportunidades que me deram. Agradeço a toda a minha família pelo apoio incondicional não só durante o mestrado, mas em todos os momentos em que precisei. Vocês são muito importantes na minha vida!

Ao Rafael, namorado e companheiro de todas as horas, agradeço por toda a ajuda com o trabalho, já que não foram poucas as planilhas, tabelas e consultorias, e também por me ajudar comigo mesma, com as palavras de conforto quando eu mais preciso.

Um grande agradecimento à minha orientadora, Profa. Dra. Ana Cristina, por confiar a mim este projeto do qual tenho orgulho de fazer parte. Obrigada pela paciência e por todo o conhecimento que me foi passado durante esses dois anos. A todos os colegas que fizeram parte desse projeto: Letícia, Raphael, Elias, Andréa, Tainá e aos colegas do mestrado, obrigada por toda ajuda com as coletas, artigos e por compartilhar seus conhecimentos comigo. Agradeço a todos os professores que fizeram parte da minha formação e aos funcionários da FEF e do PPGEF que contribuíram de alguma forma para a realização da pesquisa e a conclusão do trabalho.

Obrigada aos meus amigos da academia Body Work pela compreensão com minhas horas reduzidas de trabalho graças às muitas horas de estudo. $E$ a todos os meus amigos pelo apoio durante esse período e por estarem sempre presentes na minha vida.

Obrigada às equipes do Centro Educacional São Camilo, Escola Parque 210/211 norte e Programa Infanto Juvenil (PIJ) da UnB por abrirem as portas de suas escolas. $\mathrm{E}$ a todos os participantes e seus responsáveis por aceitarem fazer parte desta pesquisa. 
PAULA RIBEIRO MESQUITA

\section{DISTRIBUIÇÃO DA PRESSÃO PLANTAR DURANTE O ANDAR E O CORRER EM CRIANÇAS DE 4 A 10 ANOS}

Dissertação aprovada como requisito parcial para obtenção do título de mestre em educação física pelo Programa de Pós-Graduação da Faculdade de Educação Física da Universidade de Brasília.

Banca examinadora:

Profa. Dra. Ana Cristina de David

(Orientadora - PPGEF/UNB)

Prof. Dr. Tiago Guedes Russomano

(Examinador Interno - UNB)

Profa. Dra. Deyse Borges Koch

(Examinador Externo - UDESC)

Profa. Dra. Lídia Mara Aguiar Bezerra

(Examinador Suplente - PPGEF/UNB)

BRASÍLIA - DF, 30 de julho de 2015 


\section{SUMÁRIO}

LISTA DE TABELAS

LISTA DE FIGURAS..................................................................................... vii

LISTA DE SIGLAS, ABREVIAÇÕES E SÍMBOLOS..............................................viii

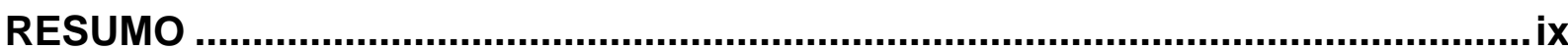

ABSTRACT

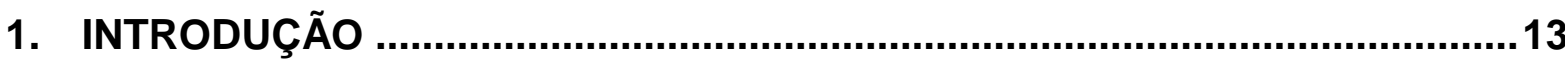

2. OBJETIVOS

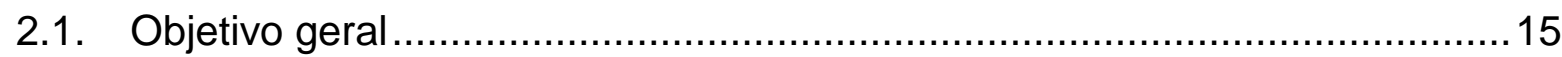

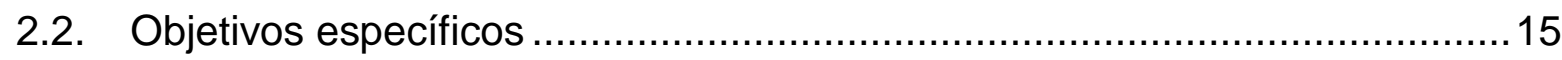

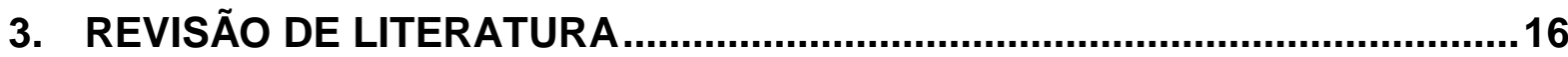

3.1. O Desenvolvimento da Marcha ...............................................................16

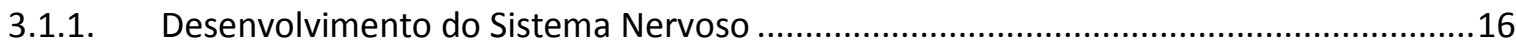

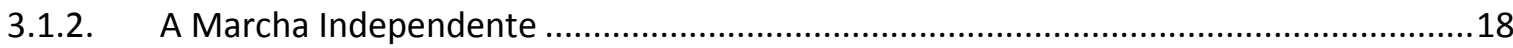

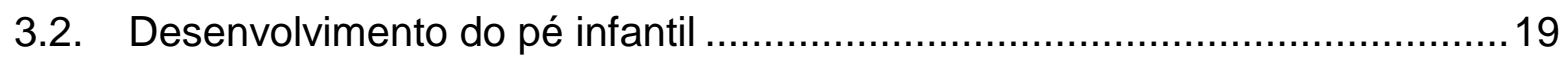

3.3. Distribuição da Pressão Plantar ...........................................................20

3.3.1. Distribuição da Pressão Plantar Durante o Andar............................................................

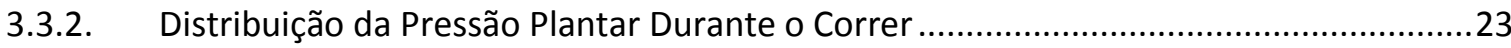

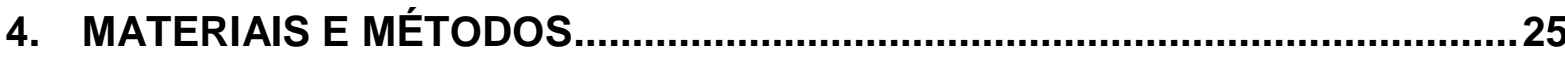

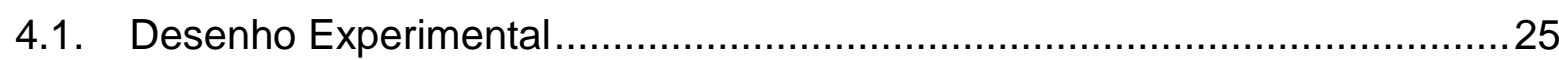

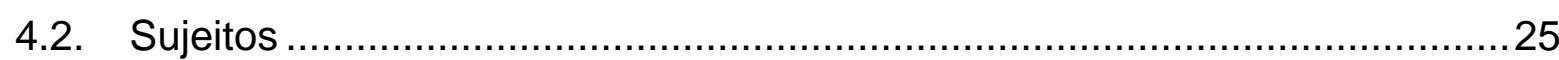

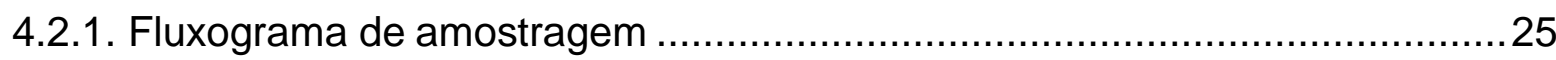

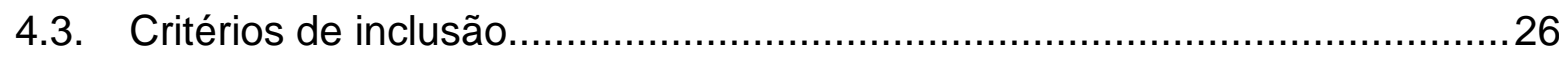

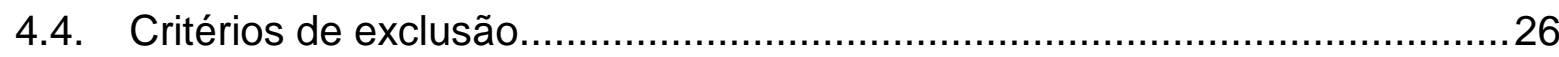

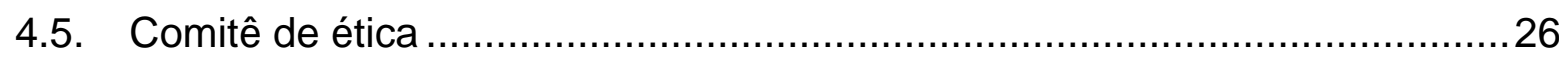

4.6. Procedimentos e instrumento de coleta ..............................................26

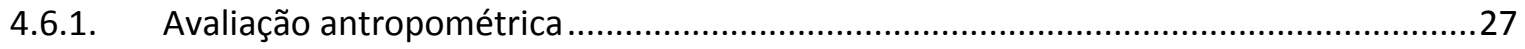

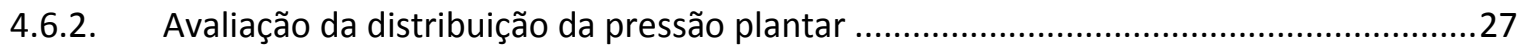

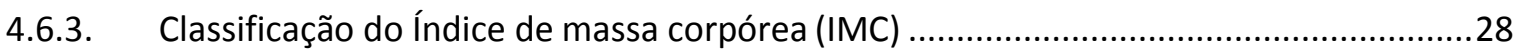

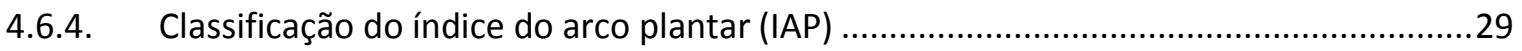

4.8. Procedimentos de análise estatística ................................................... 33

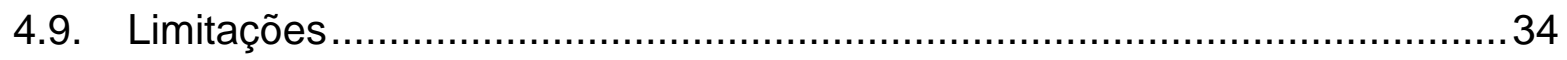




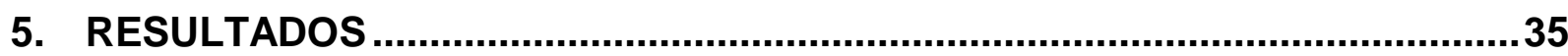

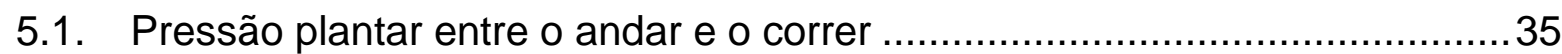

5.2. Correlação entre variáveis de pressão plantar e idade .............................42

5.3. Correlação entre variáveis de pressão plantar e variáveis morfológicas ......43

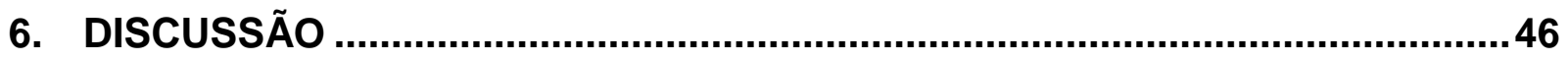

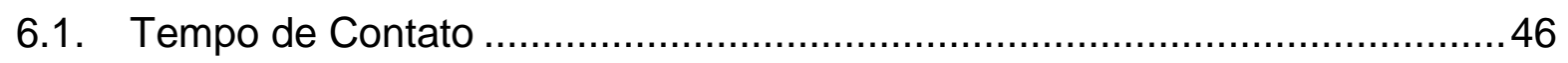

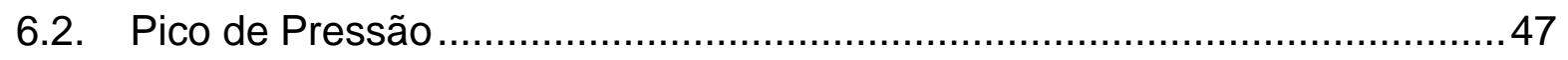

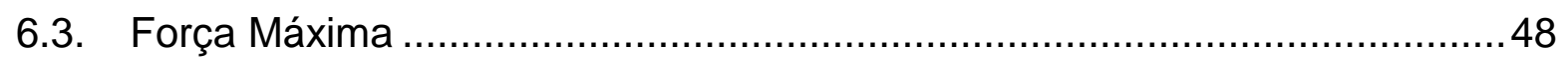

6.4. Força Máxima Normalizada ....................................................... 49

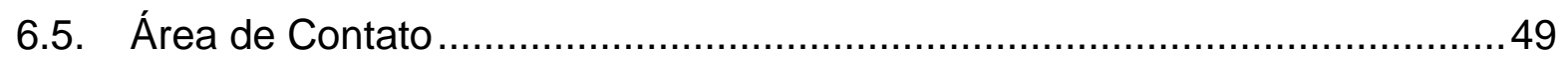

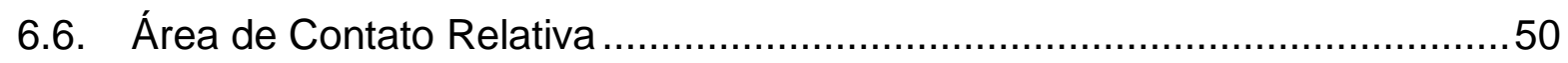

6.7. Relação entre distribuição da pressão plantar, idade e variáveis morfológicas 50

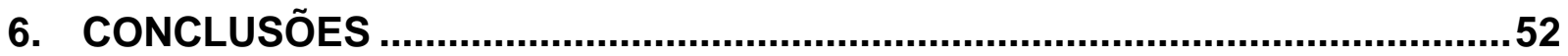

7. REFERÊNCIAS BIBLIOGRÁFICAS .............................................................53

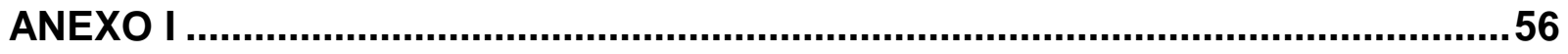

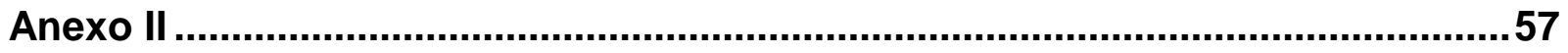

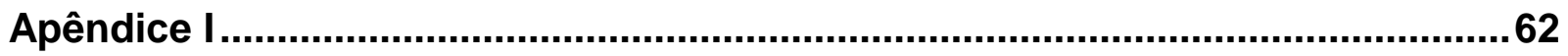

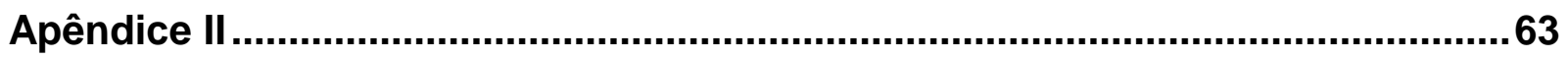

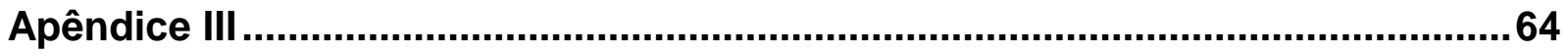

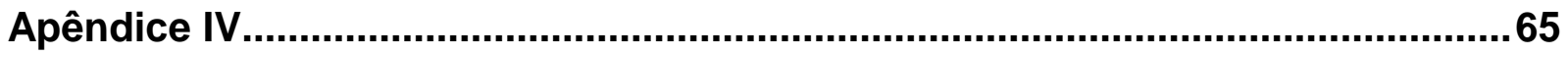

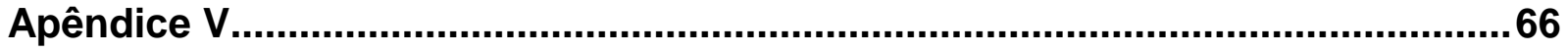




\section{LISTA DE TABELAS}

Tabela 1 - Valores de referência do corte de Cole et al para classificação de crianças de acordo com oIMC

Tabela 2 - Valores de referência para a classificação do arco longitudinal plantar...29

Tabela 3 - Dados antropométricos dos participantes do estudo 33

Tabela 4 - Diferenças entre o andar e o correr para a variável tempo de contato relativo nas regiões de análise do pé 34

Tabela 5 - Diferenças entre o andar e o correr para a variável pico de pressão nas regiões de análise do pé 35

Tabela 6 - Diferenças entre o andar e o correr para a variável força máxima nas regiões de análise do pé 36

Tabela 7 - Diferenças entre o andar e o correr para a variável força máxima relativa nas regiões de análise do pé

Tabela 8 - Diferenças entre o andar e o correr para a variável área de contato nas regiões de análise do pé

Tabela 9 - Diferenças entre o andar e o correr para a variável área de contato relativa nas regiões de análise do pé.

Tabela 10 - Correlação entre idade e as variáveis de pressão plantar 41

Tabela 11 - Correlação entre as variáveis morfológicas e as variáveis de pressão plantar. 42 


\section{LISTA DE FIGURAS}

Figura 1 - Representação das fases da marcha

Figura 2 - Representação do processo de coleta e exclusão dos sujeitos para se chegar ao número final de participantes do estudo 23

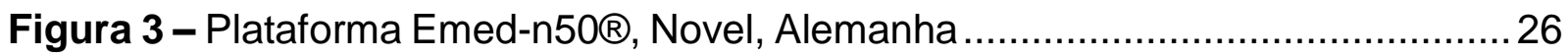

Figura 4 - Representação das marcações na impressão plantar para o cálculo do

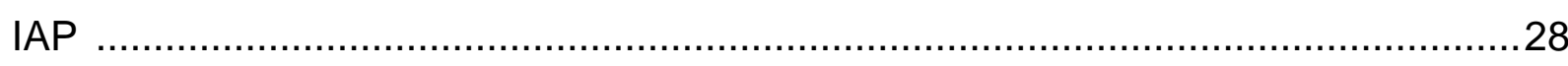

Figura 5 - Representação dos tipos de classificação do arco plantar. .......................29

Figura 6 - Imagem da divisão do pé em 5 regiões gerada pelo software Emed/R (Novel,Alemanha). 
LISTA DE SIGLAS, ABREVIAÇÕES E SÍMBOLOS

$\begin{array}{ll}\text { SNC } & \text { Sistema Nervoso Central } \\ \text { DPP } & \text { Distribuição da Pressão Plantar } \\ \mathrm{ms} & \text { Milissegundos } \\ \mathrm{kPa} & \text { Quilopascal } \\ \mathrm{N} & \text { Newton } \\ \mathrm{cm}{ }^{2} & \text { Centímetros quadrados } \\ \mathrm{IMC} & \text { Índice de Massa Corpórea } \\ \mathrm{kg} & \text { Quilogramas } \\ \mathrm{cm} & \text { Centímetros } \\ \mathrm{mm} & \text { Milímetros } \\ \mathrm{EVA} & \text { Etinil Vinil Acetato } \\ \mathrm{m} & \text { Metros } \\ \text { IAP } & \text { Índice do Arco Plantar } \\ \text { TC\% } & \text { Tempo de Contato Relativo } \\ \text { PP } & \text { Pico de Pressão } \\ \text { Fmáx } & \text { Força Máxima } \\ \text { Fmáx\% } & \text { Força Máxima Relativa } \\ \text { AC } & \text { Área de Contato } \\ \text { AC\% } & \text { Área de Contato Relativa } \\ \mathrm{Hz} & \text { Hertz } \\ \mathrm{CP} & \text { Comprimento do Pé } \\ & \end{array}$




\section{RESUMO}

\section{DISTRIBUIÇÃO DA PRESSÃO PLANTAR DURANTE O ANDAR E O CORRER EM CRIANÇAS DE 4 A 10 ANOS}

Autora: Paula Ribeiro Mesquita

Orientadora: Ana Cristina de David

A distribuição da pressão plantar tem sido descrita como uma indicadora das cargas impostas ao sistema musculoesquelético durante as atividades dinâmicas e pode fornecer informações a respeito do funcionamento do pé durante o deslocamento. Objetivo: Descrever e comparar a distribuição da pressão plantar durante o andar e o correr em crianças eutróficas de 4 a 10 anos. Métodos: Foram coletados os dados da pressão plantar de 103 crianças eutróficas entre 4 e 10 anos de idade, utilizando a plataforma Emed n-50® (Novel, Alemanha) durante o andar e o correr em velocidade auto selecionada. O tempo de contato relativo, o pico de pressão e a força máxima e a área de contato absolutas e relativas foram analisados em 5 regiões (calcanhar, mediopé, antepé, hálux e dedos), além da área total do pé. Resultados: As variáveis morfológicas peso, estatura, índice de massa corpórea (IMC) e comprimento do pé apresentaram aumentos graduais e contínuos, enquanto o índice do arco plantar (IAP) sofreu decréscimos com 0 aumento da idade. As cargas plantares e a área de contato do pé foram maiores durante o correr em relação ao andar, entretanto, foram observados alguns aumentos das variáveis para o andar na região do calcanhar. As diferenças entre o andar e o correr puderam ser observadas tanto para variáveis absolutas quanto para aquelas com valor normalizado. $\mathrm{Na}$ análise da correlação entre a pressão plantar e a idade, foi encontrada influência da idade sobre a pressão plantar, com tendência a aumento das variáveis nas regiões do calcanhar, antepé, hálux e dedos, e reduções na área do mediopé. As variáveis morfológicas também apresentam correlações significativas com a distribuição da pressão plantar, principalmente com as variáveis absolutas força máxima e área de contato. A força máxima relativa apresentou correlações negativas com a idade, o peso e a estatura 
e as correlações significativas com o índice do arco plantar foram encontradas principalmente para a área de contato relativa em todas as regiões do pé e para as demais variáveis na região do mediopé. Conclusão: Os resultados indicam que os valores das variáveis de pressão plantar são mais altos para o correr em relação ao andar em crianças de 4 a 10 anos. Maiores cargas plantares podem estar associadas aos aumentos no peso corporal e estatura dos participantes e as tendências de valores crescentes das variáveis plantares no calcanhar, antepé, hálux e dedos, e decrescentes no mediopé, estão possivelmente associadas ao processo de maturação das crianças. Essas relações entre a pressão plantar e 0 processo maturacional ocorrido com o aumento da idade são corroboradas pelas correlações significativas encontradas entre a pressão plantar, a idade e as variáveis morfológicas. Os dados podem ser utilizados como referência para comparação com estudos que avaliem o andar e o correr de crianças e adultos. 


\begin{abstract}
PLANTAR PRESSURE DISTRIBUTION DURING WALKING AND RUNNING IN CHILDREN AGED 4 TO 10 YEARS OLD
\end{abstract}

\author{
Author: Paula Ribeiro Mesquita \\ Adviser: Ana Cristina de David
}

Plantar pressure distribution has been described as an indicator of the load patterns imposed on the musculoskeletal system during dynamic activities and can provide information regarding foot function during motion. Objective: Describe and compare plantar pressure distribution during walking and running in eutrophic children aged 4 to 10 years old. Methods: Plantar pressure distribution data from 103 eutrophic children aged 4 to 10 years old were acquired using the Emed n-50 $\circledast$ (Novel, Germany) platform during walking and running on self-selected speed. The relative contact time, peak pressure and absolute and relative values of maximum force and contact area were analyzed under 5 foot regions (hindfoot, midfoot, forefoot hallux and toes) and the total area of the foot. Results: Body weight and height, body mass index (BMI) and foot length showed gradual and continuous increases while arch index (Al) was reduced with increasing age. Plantar loads and contact area were higher during running in comparison to walking, however, increases were also observed under the hindfoot during walking. Differences between walking and running could be observed both for absolute and normalized variables. In the analysis of correlation between plantar pressure and age, it was found that age influenced plantar pressure, tending to increase variables values under the heel, forefoot, hallux and toes, and reduce them under the midfoot area. Morphological variables also showed significant correlations with plantar pressure distribution, especially with absolute maximum force and contact area. Relative maximum force showed negative correlations with age, body weight and height. Significant correlations with the plantar arch index were mainly found with relative contact area under all regions of the foot and under the midfoot region with the other plantar pressure variables. Conclusion: Results indicate that running has higher values of plantar pressure variables than walking in children aged 4 to 10 years. 
Increases in plantar loads may be associated with increasing body weight and height and trends of variables increasing variable values under the hindfoot, forefoot, hallux and toes, and decrease under the midfoot, are possibly associated with the maturation process of children. These associations between plantar pressure and the maturation process that occurs with increasing age are supported by the significant correlations that were found between plantar pressure, age and morphological variables. Data may be used as reference for comparison with studies evaluating walking and running in children and adults. 


\section{INTRODUÇÃO}

A marcha é um tipo de locomoção de padrão bípede que envolve os sistemas nervoso e musculoesquelético, exigindo interações complexas entre as articulações do corpo e diversos processos coordenativos gerados pelo sistema sensório-motor (1). Durante a infância o sistema musculoesquelético está sujeito a uma série de alterações resultantes do processo de maturação. Os parâmetros de tamanho e formato do pé e os padrões de movimento do andar apresentam diferenças típicas na comparação com adultos, além de uma variabilidade existente entre as próprias crianças $(2,3)$.

O início do apoio bipodal e da marcha independente gera forças de compressão e tensão importantes para desencadear as mudanças ósseas e musculares que são necessárias para preparar o corpo para as futuras demandas de sobrecarga durante o movimento (2). A avaliação da distribuição da pressão plantar tem sido relatada como indicadora dos padrões de cargas impostas ao sistema musculoesquelético em situações estáticas e dinâmicas e, em geral, é considerada como um método confiável para avaliação dos parâmetros de formato, da eficiência mecânica do movimento e do funcionamento do pé (4).

Os padrões de distribuição da pressão plantar são avaliados por meio da observação de variáveis plantares, tais como pressão, força e tempo e área de contato, considerando suas relações com alguns fatores antropométricos, biológicos e biomecânicos. Seus valores têm sido estudados com o objetivo de estabelecer referências para a caracterização do desenvolvimento do pé da criança saudável.

Dados sobre a distribuição da pressão plantar durante a marcha de crianças foram publicados e os principais resultados indicam o aumento das cargas plantares durante o crescimento $(2,4,5)$. Os valores de tempo de contato tendem a ser menores, bem como os índices de assimetria do movimento, uma vez que a criança ganha segurança e estabilidade com o aumento da idade $(3,6)$. A área de contato, por sua vez, apresenta valores maiores ao longo tempo, pois está associada ao aumento do comprimento do pé (2-4).

Comparações entre gêneros tem trazido resultados contraditórios. $O$ estudo de Phetean e Nester (7) com crianças de desenvolvimento típico e idades entre 4 e 7 anos não encontrou diferenças entre meninos e meninas enquanto que outros 
estudos apresentam algumas diferenças como um mediopé mais largo e uma maior incidência de pé-plano nos meninos, indicando um desenvolvimento mais lento do arco longitudinal plantar $(2,5,8)$.

Também foi relatada a relação entre os dados da pressão plantar e variáveis morfológicas, que demonstrou que os aumentos no peso corporal e na estatura influenciam as cargas plantares (2). Crianças obesas parecem estar sujeitas a maiores pressões, especialmente na região medial do pé $(9,10)$.

Outro fator que exerce influência sobre a pressão plantar é a velocidade de execução do movimento. Estudos demonstram que o aumento da velocidade durante a marcha pode alterar tanto variáveis espaço-temporais, quanto as variáveis plantares (11-14). As cargas na planta do pé crescem com o aumento da velocidade, podendo chegar a até 5 vezes o peso corporal durante a corrida $(15,16)$.

Os estudos existentes sobre a distribuição de pressão plantar durante o correr avaliam com maior recorrência adultos ou jovens atletas, buscando entender a relação entre as forças geradas pelo movimento e sua relação com riscos, prevenção e tratamento de lesões. Os estudos de Fourchet et al (17) e Ho et al (18) compararam o correr em diferentes velocidades e encontraram, em velocidades mais altas, aumentos nos valores de pressão, força e área de contato e redução do tempo de contato com o solo.

A análise do desenvolvimento do andar e do correr representa um campo importante para a compreensão do processo maturacional. Dados normativos sobre as cargas plantares durante o deslocamento podem facilitar a caracterização e a distinção entre um desenvolvimento fisiológico típico e patológico e contribuir para intervenções tanto em programas de treinamento e esporte escolar como em aplicações clínicas. No entanto, não foram encontrados dados publicados sobre a distribuição da pressão plantar durante o correr em crianças. 


\section{OBJETIVOS}

\subsection{Objetivo geral}

Comparar o comportamento da distribuição da pressão plantar durante o andar e o correr em crianças de 4 a 10 anos.

\subsection{Objetivos específicos}

- Descrever o comportamento das variáveis da pressão plantar durante o andar e correr para cada idade;

- Verificar a correlação entre as variáveis da pressão plantar e a idade;

- Verificar a correlação entre as variáveis da pressão plantar e variáveis morfológicas.

\subsection{Hipóteses}

- Os valores de pressão plantar são maiores durante o correr em relação ao andar;

- O aumento da idade pode influenciar a distribuição da pressão plantar;

- As variações nas variáveis morfológicas durante o crescimento podem influenciar a distribuição da pressão plantar. 


\section{REVISÃO DE LITERATURA}

\subsection{O Desenvolvimento da Marcha}

O movimento é descrito como o comportamento de um membro específico ou de uma combinação deles, sendo, assim, parte integrante de uma habilidade motora (19). Os movimentos corporais possuem diversas finalidades, tais como a manutenção postural e a locomoção. A regulação do comportamento motor em todos os casos é feita fundamentalmente pelo disparo de comandos motores a partir do sistema nervoso central (SNC) (20).

\subsubsection{Desenvolvimento do Sistema Nervoso}

O sistema nervoso tem o seu desenvolvimento iniciado ainda nas primeiras semanas de gestação. Quando o embrião está sendo constituído, o processo de divisão celular se dá de forma acelerada e começam a ser formadas as estruturas que originarão os sistemas nervosos central e periférico (21). $O$ desenvolvimento das funções neuromotoras também é iniciado ainda no período intrauterino e pode ser observado nos reflexos primitivos que se manifestam nos primeiros meses após o nascimento e que vão desaparecendo ao longo do primeiro ano de vida devido à maturação do sistema nervoso central e a emergência da capacidade de controle motor voluntário (20). Os atos motores são ordenados por regiões corticais e subcorticais que comandam as ações contráteis das unidades motoras por meio de dois sistemas fundamentais: medial - que exerce os controles de equilíbrio e postura conectados principalmente aos sistemas axiais e proximais; e lateral que reúne as vias de comando dos movimentos voluntários finos efetuados principalmente pelas partes mais distais dos membros (21).

Dentre as finalidades dos movimento corporais, destaca-se a locomoção, que acontece, principalmente, por meio da marcha e tem como objetivo realizar o deslocamento até um ponto desejado, em velocidade autodeterminada e com o menor gasto energético possível (22). Esse objetivo pode ser executado com eficiência graças à simetria que existe entre os movimentos angulares das principais articulações envolvidas e aos padrões de ativação muscular e sustentação de carga dos membros inferiores (1). 
Esses padrões de simetria e coordenação são desenvolvidos ao longo dos anos à medida em que ocorrem os processos maturacionais dos sistemas nervoso e musculoesquelético com o desenvolvimento dos sistemas de controle do tônus muscular e das reações posturais e antecipatórias (21).

O tônus muscular é o nível de tensão basal, ou o estado de contração permanente de um músculo. Os níveis de contração são delicada e precisamente controlados pelo sistema nervoso, ajudando a armazenar energia mecânica e mantendo o sistema preparado para responder às alterações de posição do corpo que são provocadas por mudanças ambientais ou pela própria vontade do indivíduo. O mecanismo responsável por auxiliar o indivíduo a manter ou atingir uma posição desejada é o reflexo de estiramento, que trabalha nos ajustes musculares de baixa magnitude em resposta a pequenas perturbações do movimento $(20,21,23)$. Além dos ajustes de tônus muscular, o sistema nervoso apresenta cadeias reflexas específicas para permitir, durante o movimento, a realização de ajustes posturais com eficiência, são as chamadas reações posturais (21). Na locomoção, os dois mecanismos trabalham em conjunto, com o objetivo de manter e ajustar os níveis adequados de contração muscular e a posição do corpo para que o padrão de movimento seja o mais estável possível.

Durante a marcha, os circuitos neurais responsáveis pelo controle do movimento realizam boa parte da coordenação entre os diferentes grupos musculares por meio dos centros geradores de padrões rítmicos, que são capazes de controlar a sincronização temporal e a coordenação dos padrões de movimento, além de realizar ajustes em diversas circunstâncias $(21,23)$. Esses centros são responsáveis pelo comando sequencial dos músculos durante a locomoção e trabalham formando circuitos oscilatórios que envolvem motoneurônios extensores e flexores em um ciclo de duas fases (Figura 1): a fase de apoio, na qual os extensores da perna são ativados e os flexores inibidos, mantendo o contato do membro com o solo. E a fase de balanço, quando o membro é flexionado para se afastar do solo e, então, levado à frente para iniciar a próxima fase de apoio. As fases acontecem de maneira unilateral, quando um membro se encontra na fase de apoio, o outro está em fase de balanço. No ciclo seguinte, inverte-se o padrão, e assim sucessivamente (2123). Aumentos na velocidade de locomoção reduzem a quantidade de tempo 
necessário para completar um ciclo, e a principal alteração no tempo do ciclo acontece devido a um encurtamento da fase de apoio (23).

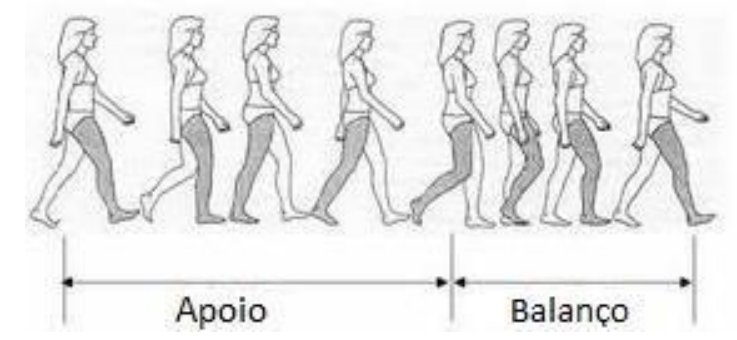

Figura 1. Representação das fases da marcha.

(Fonte: Site Flagrante Urbano ${ }^{1}$ )

\subsubsection{A Marcha Independente}

O processo de desenvolvimento motor é caracterizado pelas alterações que acontecem em um comportamento para a execução de uma certa habilidade. Depois que o controle voluntário dos movimentos é adquirido, as habilidades motoras rudimentares são iniciadas e surgem em uma sequência lógica de desenvolvimento. Inicialmente, são estabelecidas as relações entre o corpo e a força da gravidade, desenvolvendo as tarefas de estabilidade necessárias para sustentação do corpo e sem as quais a criança não conseguirá se movimentar livremente. Em seguida, temos a aquisição das habilidades de locomoção que se dá por meio de uma progressão sequencial iniciada pelo rastejar, que surge, geralmente, entre o quarto e o sexto mês de vida. $O$ ato de engatinhar evolui da habilidade de arrastar-se e se diferencia desta por apresentar o padrão contralateral de ativação dos membros. A aquisição da locomoção na postura ereta, ou marcha, depende do desenvolvimento das habilidades estabilizadoras, pois a criança deve ser capaz de controlar o corpo durante o apoio bipodal antes de dominar as mudanças posturais dinâmicas que ocorrem durante o deslocamento. Essa sequência pode apresentar variações resultantes de influências biológicas, ambientais ou de tarefa (24).

A marcha apresenta seu estágio inicial, por volta dos 12-14 meses e é caracterizada por um ciclo de movimento instável, com uso limitado ou exagerado do corpo e fluxo rítmico e coordenação deficientes que estão relacionados às limitações de controle postural e habilidades coordenativas da criança $(5,24)$. O desenvolvimento básico dessas habilidades acontece de 3

\footnotetext{
${ }^{1}$ Disponível em<https://flagrantesurbanos.webnode.com.br/products/a-marcha-nossa-de-cada-dia> Acessado em jul. 2014.
} 
a 6 meses após o início da marcha independente, mas perdura ainda por cerca de 4 anos para que sejam realizados ajustes finos do movimento às mudanças ocorridas em razão do processo de maturação anatômica e neural (25-27). Isso acontece porque, após adquirir uma habilidade, o indivíduo necessita de algum tempo de prática para se adequar ao movimento, ajustando ao seu corpo em crescimento e, assim, desenvolver um padrão maduro de coordenação de movimento dos membros (19). Dessa forma, as mudanças anatômicas e adaptações posturais que ocorrem de maneira acelerada nos primeiros anos de vida representam um fator importante durante o período de aprendizagem do andar para que se atinja um padrão de movimento estável, o que ocorre por volta dos 5 anos de idade $(25,26)$. Segundo o modelo teórico apresentado por Gallahue e Ozmun (24), o auge do processo de desenvolvimento motor, caracterizado pelo uso do repertório de movimentos adquiridos pelo indivíduo durante toda a vida, acontece por volta dos 14 anos de idade.

\subsection{Desenvolvimento do pé infantil}

A marcha é uma tarefa funcional que exige interações complexas e coordenação entre muitas das principais articulações do corpo, especialmente nos membros inferiores (1). Com uma biomecânica complexa e uma das estruturas mais ergonomicamente eficientes do corpo humano, o pé é uma parte mecânica integrante do membro inferior, necessária para proporcionar um andar suave e estável, visto que exerce a função de uma estrutura semirígida, sustentando e distribuindo altos valores de pressão durante o apoio, e servindo como uma alavanca no momento da propulsão, além de fornecer informações sensoriais a respeito do contato com o solo $(1,28,29)$. Dessa forma, qualquer alteração patológica durante o desenvolvimento da estrutura do pé pode exercer impacto nas suas funções de absorção, propulsão e estabilização (28).

A maturação do pé infantil é influenciada pelo início do apoio bipodal e da marcha independente. A ossificação do pé acontece de forma contínua até por volta de 5 anos de idade, e o calcanhar sofre uma remodelação que é causada por uma combinação de carga estática e atividade muscular. Nos anos iniciais, a região medial do pé ainda é preenchida por uma camada de tecido adiposo 
que aumenta a área de contato da região com o solo e auxilia na amortização e absorção das cargas impostas ao sistema musculoesquelético, evitando sobrecargas até que o sistema esteja adaptado à posição em apoio bipodal (3, $5,28,30)$.

Ao longo dos primeiros 5-6 anos de vida, essa camada de tecido adiposo vai sendo absorvida e começa a dar lugar ao arco longitudinal plantar. Esse processo acontece de forma mais acelerada nos primeiros anos, e, após isso, continua gradativamente até, em média, os 10 anos de idade $(3,31)$. Podemos considerar que o desenvolvimento do arco plantar estabelece uma relação com o início do apoio bipodal e a marcha já que as consequentes cargas e pressões exercidas sob o pé nesse período são importantes para desencadear alterações nas estruturas ósseas e musculares, de maneira a prepará-las paras as futuras necessidades de sustentação e absorção de sobrecargas na planta do pé $(2,32)$. A idade com que a marcha independente é iniciada, no entanto, não exerce influência sobre o desenvolvimento maturacional do pé. Segundo relatado por Bosch e colaboradores em um estudo longitudinal (2), os parâmetros de desenvolvimento do pé não diferiram entre as crianças com aquisição prematura ou tardia da marcha.

O desenvolvimento do pé também pode ser acompanhado por meio de parâmetros do seu formato obtidos por meio da impressão plantar, como comprimento e largura. Resultados indicaram aumentos significativos para 0 comprimento do pé com a idade (2-4), representando o processo de crescimento no qual cerca de $50 \%$ do comprimento final é atingido por volta de 12-18 meses, e que tem continuidade de forma gradualmente mais lenta até os 5 anos de idade $(5,33)$. Estudos relatam um crescimento médio de 8 a $10 \mathrm{~mm}$ por ano até os 12 anos nas meninas e até os 15 anos nos meninos (34). Por outro lado, são descritos valores decrescentes para a largura do pé na sua região medial, que se mostram relacionados ao desenvolvimento do arco longitudinal plantar após o início do apoio bipodal e da marcha (2-5).

\subsection{Distribuição da Pressão Plantar}

O pé e o tornozelo fornecem o apoio e a flexibilidade necessários durante o movimento de rolamento para o deslocamento do peso na realização da marcha e de outras atividades dinâmicas (29). Diversos métodos podem ser 
utilizados para avaliar a ação de forças sobre a estrutura do complexo pétornozelo durante as atividades funcionais. A análise do comportamento da superfície plantar é realizada por meio de um indicador dos padrões de carga impostos ao sistema musculoesquelético durante essas atividades, esse indicador é a distribuição da pressão plantar (DPP).

Ao avaliar a DPP, um sensor discreto ou uma matriz de sensores múltiplos é utilizada para medir a força atuante sobre cada um dos sensores durante 0 contato do pé com a superfície. A magnitude da pressão é então determinada pela razão entre a força medida e a área conhecida dos sensores ativados $A$ avaliação da atuação da pressão em cada região do pé permite estabelecer valores normativos de referência para um desenvolvimento típico e contribuem para a identificação de patologias relacionadas à locomoção (35).

Análises da distribuição da pressão plantar podem ser realizadas tanto em situações estáticas como em situações dinâmicas, como o andar e o correr. Entre as variáveis de distribuição da pressão mais utilizadas estão: Tempo de Contato - que representa o tempo em que o pé mantém contato com a superfície da plataforma em milissegundos (ms) ou em porcentagem do tempo total de contato; Pico de Pressão - representado pelo maior valor de pressão registrado em quilopascal $(\mathrm{kPa})$ por cada sensor durante a fase de apoio; Força Máxima - descrita pelo somatório dos valores de força em newton (N) registrados durante o contato, podendo ser um valor absoluto ou normalizado pelo peso corporal; e Área de Contato - descrita pela região do pé onde as forças são aplicadas e também pode ter valores absolutos, em centímetros quadrados $\left(\mathrm{cm}^{2}\right)$ ou relativos, em porcentagem da área total (35).

\subsubsection{Distribuição da Pressão Plantar Durante o Andar}

A distribuição da pressão plantar durante a marcha de crianças está bem descrita na literatura e traz alguns dados que podem ser utilizados como referência para comparação com outros estudos.

A relação entre as variáveis morfológicas e os dados da pressão plantar parece ser importante para o entendimento do processo de maturação. Um estudo longitudinal (2) relatou que o aumento da estatura está relacionado a maiores valores das variáveis força máxima, área de contato e pico de pressão nas regiões do calcanhar, antepé e hálux, além da área total e a um 
decréscimo na região do mediopé. Foi apresentada ainda a influência do peso corporal, que, quando aumentado, levou a acréscimos na região do mediopé para a força máxima, área de contato, pico de pressão e índice do arco plantar. Por outro lado, o aumento do peso corporal resultou em reduções da força máxima nas regiões do calcanhar, antepé, hálux e dedos e do pico de pressão na área total do pé, no calcanhar e nos dedos. Crianças obesas parecem estar sujeitas a maiores valores de carga principalmente na região medial do pé $(9$, 10).

$\mathrm{Na}$ análise das variáveis dinâmicas da pressão plantar, um estudo com crianças relatou valores decrescentes para o tempo de contato relativo durante o primeiro ano de marcha independente, indicando o ganho de segurança e estabilidade durante o andar (3). Uma análise do índice de assimetria da marcha em relação ao tempo de contato absoluto, relatou que a simetria do movimento foi obtida a partir de 2,5 anos de idade (6).

Os resultados apresentados para o pico de pressão demonstraram aumentos graduais, que indicam a continuidade do crescimento do pé após os 10 anos e demonstram o processo de desenvolvimento do padrão da marcha $(2,5)$. Nos primeiros meses após a aquisição da marcha, os picos de pressão foram vistos sob o hálux, o que parece ser uma característica desse primeiro momento $(2,5,36)$, mas, ao longo do primeiro ano, os valores de pico de pressão passam a se apresentar na região do calcanhar devido ao desenvolvimento de um padrão com ataque inicial do calcanhar $(2,5)$.

Outra variável indicadora de uma melhor dinâmica da marcha, é a força máxima, que também apresentou valores crescentes com o aumento da idade (2). Esse comportamento pode ser visto tanto para valores absolutos quanto para valores normalizados pelo peso corporal (3). Em estudo sobre a simetria da marcha, verificou-se que, com o aumento da idade, o índice de assimetria da força diminui e, consequentemente, a assimetria do movimento como um todo (6). A área de contato do pé, assim como o comprimento, pode ser um indicador dos níveis de maturação da criança. Estudos demonstram áreas absolutas e relativas maiores com o aumento da idade (2-4).

A região medial do pé tende a apresentar valores menores das variáveis de pressão plantar com o aumento da idade, fato que é justificado pelo desenvolvimento do arco longitudinal plantar $(2,4,5)$. $O$ índice do arco plantar 
também pode ser utilizado como indicador de desenvolvimento, sendo que o aumento da idade está associado a valores decrescentes, indicando arcos longitudinais mais desenvolvidos (2, 4). Na comparação com adultos, as crianças apresentam valores significativamente mais altos, indicando um arco plantar mais baixo, ou seja, menos desenvolvido (37). Valores de índice do arco plantar próximos ao do pé adulto são atingidos por volta dos 7 anos de idade (4).

Comparando o comportamento das variáveis de pressão plantar entre meninos e meninas, os resultados são contraditórios. Foi encontrado tanto um estudo que não apresentou diferenças significativas entre meninos e meninas (7), quanto alguns que encontraram diferenças para o pico de pressão na região do hálux, sendo os valores nos pés dos meninos mais altos que nos das meninas (5), e uma importante diferença na largura do mediopé, que é maior para os meninos $(2,5)$, assim como a incidência de pé-plano. Essas características são justificadas pelo fato de que os meninos possuem uma camada mais espessa de tecido adiposo na região medial do que as meninas, o que sugere que o desenvolvimento do seu arco longitudinal plantar ocorra de forma mais lenta (8).

Estudos relatam que o aumento da idade tende a gerar aumentos de velocidade durante a marcha em crianças, no entanto, essa diferença observada entre as idades pode estar associada à diferença de tamanho entre os sujeitos. A variação na velocidade pode influenciar tanto variáveis espaçotemporais, quanto variáveis de pressão plantar (11-14).

\subsubsection{Distribuição da Pressão Plantar Durante o Correr}

A quantidade de energia gerada pelos sistemas muscular e articular durante a corrida é maior do que durante a marcha, resultando em maiores forças de reação do solo (38). Durante o andar, as cargas podem ser de 1,3 a 1,5 vezes o peso corporal, enquanto que, durante o correr, os valores são significativamente maiores, chegando a até 5 vezes o peso corporal $(15,16$, 39). Na infância, os padrões do correr começam a ser desenvolvidos entre 13 e 18 meses, período em que a criança ainda executa o movimento sem a fase de voo. A fase de voo do correr, representada pelo momento no qual os dois pés perdem o contato com o solo, pode começar a ser observada por volta dos 
3 anos de idade $(5,24,38)$. Valores elevados de pressão plantar são considerados um fator de risco para o desenvolvimento do pé, e podem estar associados a diversas patologias, por isso, a análise da distribuição da pressão plantar durante o correr pode ser importante para fornecer informações a respeito do funcionamento do complexo pé-tornozelo durante o movimento (40). A maior parte dos estudos que analisam a DPP durante o correr traz informações sobre populações de adolescentes e adultos, com enfoque na prevenção e nos possíveis riscos associados às lesões $(17,18,41)$.

Alguns fatores podem influenciar a distribuição da pressão plantar, tais como o tipo de calçado utilizado, o tipo de pisada e a velocidade de locomoção. O padrão de deslocamento das cargas aplicadas durante o correr podem ser significativamente alterados pelo uso de calçados, podendo mudar a aplicação da pressão para diferentes estruturas anatômicas do pé (38). O tipo de pisada pode ser caracterizado pela colisão do pé com o solo acontecendo de diferentes formas: (I) retropé, quando o contato inicial é feito em algum lugar no calcanhar ou no terço traseiro do pé; (II) mediopé, no qual calcanhar e metatarsos entram em contato com o solo praticamente ao mesmo tempo (geralmente ao longo da margem lateral); e (III) do antepé, em que o contato inicial é feito no terço anterior do pé, com o contato do calcanhar, normalmente, acontecendo logo em seguida. Uma variabilidade significativa na DPP durante o correr pode ser observada entre os corredores que pisam com o antepé, mediopé e o retropé (38).

Um estudo que comparou a pressão plantar em mulheres durante o correr em diferentes velocidades relatou aumentos da força máxima e dos picos de pressão em todas as regiões do pé com o ritmo crescente do correr, além de um aumento na inversão durante a fase de apoio que contribuiu para o aumento da pressão na porção lateral do pé (18). Avaliando adolescentes treinados, Fourchet et al (17) compararam a pressão plantar durante o trote e a corrida e relataram que o pico de pressão e as variáveis absolutas força máxima e área de contato na área total do pé foram significativamente maiores durante o correr, enquanto que o tempo de contato absoluto foi menor.

Embora a literatura apresente diversos estudos sobre a distribuição da pressão plantar durante $o$ andar, não foram encontrados estudos com dados sobre o correr em crianças. 


\section{MATERIAIS E MÉTODOS}

\subsection{Desenho Experimental}

O presente estudo possui caráter quantitativo, pois utiliza os dados coletados para testar hipóteses. Tendo em vista que o trabalho foi baseado na observação de dados coletados em um único momento e em sua ocorrência natural (sem manipulação do pesquisador), para que fosse possível verificar as possíveis relações entre as variáveis analisadas, a pesquisa é classificada como não-experimental, transversal e correlacional (42).

\subsection{Sujeitos}

\subsubsection{Fluxograma de amostragem}

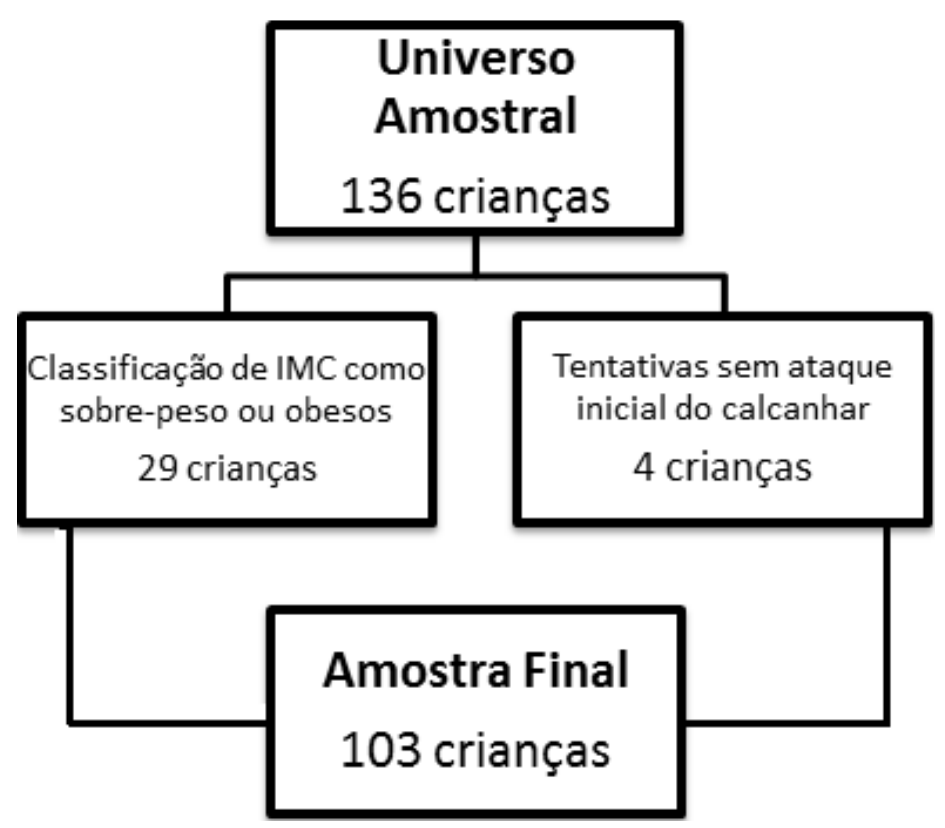

Figura 2. Representação do processo de coleta e exclusão dos sujeitos para se chegar ao número final de participantes do estudo.

Após a realização das coletas nas escolas participantes, foram excluídos da amostra as crianças que não foram classificadas como eutróficas de acordo com o cálculo do índice de massa corpórea (IMC), além daquelas que não apresentaram um padrão de movimento com ataque inicial do calcanhar durante os testes. Sendo assim, a amostra do estudo foi composta por 103 crianças eutróficas entre 4 e 10 anos de idade, estudantes de escolas públicas e particulares da Asa Norte, Distrito Federal. 


\subsection{Critérios de inclusão}

- Estar dentro da faixa etária estipulada;

- Não possuir histórico de desenvolvimento motor atípico ou de doenças e lesões que comprometessem os movimentos, de maneira a impossibilitar a realização das avaliações de forma independente (identificados por avaliação do pesquisador durante o teste, ou conforme descrito pelos pais e/ou responsáveis por meio de preenchimento de questionário - Apêndice I).

\subsection{Critérios de exclusão}

- Ser classificado como sobrepeso ou obeso de acordo com a tabela de classificação do IMC do corte de Cole et al (43);

- Executar as tentativas com padrão de movimento sem ataque inicial do calcanhar.

\subsection{Comitê de ética}

O projeto foi aprovado pelo Comitê de Ética em Pesquisa com Seres Humanos da Faculdade de Ciências da Saúde da Universidade de Brasília (UnB) sob parecer de número 988.313 (Anexo I).

\subsection{Procedimentos e instrumento de coleta}

As instituições de ensino participantes foram selecionadas por conveniência. Inicialmente, a direção foi contactada por meio de uma carta convite (Apêndice II) para esclarecimentos sobre o estudo e autorização para a realização da pesquisa no ambiente da escola por meio da assinatura de um termo de ciência institucional (Apêndice III). Após autorização da escola, foi enviado aos pais e/ou responsáveis, um Termo de Consentimento Livre e Esclarecido (Apêndice IV) e às crianças, um Termo de Assentimento (Apêndice V) explicando os objetivos e procedimentos da pesquisa, juntamente com um questionário a ser respondido sobre dados pessoais e histórico de lesões e doenças das crianças (Apêndice I). Para os alunos que obtiveram autorização dos responsáveis, e que se enquadraram nos critérios de inclusão da pesquisa, foram agendados horários para a coleta, durante o período de aulas, em uma sala disponibilizada pela direção da escola. No 
momento dos testes, as crianças deveriam estar utilizando roupas confortáveis, evitando peças que prejudicassem os movimentos ou a aquisição dos dados. No caso das coletas realizadas durante o horário das aulas, as crianças poderiam utilizar o uniforme escolar. Todas as avaliações foram feitas com os sujeitos descalços, uma vez que a utilização de calçados pode influenciar significativamente a pressão plantar $(17,41)$.

\subsubsection{Avaliação antropométrica}

Foram registrados os dados antropométricos de cada sujeito para caracterização da amostra. O peso corporal, em quilogramas $(\mathrm{kg})$ foi registrado utilizando uma balança mecânica com precisão de 0,01 kg. A estatura, em centímetros (cm), foi registrada com o sujeito posicionado de costas para a parede, de maneira que os calcanhares estivessem em contato com a mesma. Utilizou-se uma fita métrica fixada na parece, com resolução de $0,1 \mathrm{~cm}$. As crianças foram classificadas como eutróficas utilizando como referência o corte de Cole et al (43).

\subsubsection{Avaliação da distribuição da pressão plantar}

Para realização da avaliação da distribuição da pressão plantar, foi utilizado o sistema EMED-AT (Novel, Alemanha). A coleta dos dados foi realizada na plataforma de avaliação da pressão plantar Emed-n50®, Novel, Alemanha (Figura 3), conectada via USB a um computador portátil contendo o software Emed/R - Database Light 23.3.44 (próprio do sistema Emed-AT). A plataforma possui dimensões de $700 \times 403 \times 15,5$ milímetros $(\mathrm{mm})$, contendo 6.080 sensores capacitivos, uma resolução de 4 sensores $/ \mathrm{cm}^{2}$ e frequência de amostragem máxima de $50 \mathrm{~Hz}$. A plataforma de pressão fica posicionada ao centro de uma passarela de Etinil Vinil Acetato (EVA) com 3,66 metros $(m)$ de comprimento para que não haja diferença entre a altura da plataforma e o solo. As coletas foram realizadas em 4 locações diferentes, com um mínimo de 2 avaliadores presentes. Os equipamentos foram posicionados de maneira que um dos avaliadores monitorava a coleta acompanhando a criança e o outro monitorava o funcionamento do programa no computador ao qual a plataforma foi conectada. Em todos os locais de coletas, a plataforma foi posicionada de 
maneira que houvesse, no mínimo, 2 m de distância para os processos de aceleração de desaceleração durante a realização das tentativas. Todos os avaliados puderam realizar algumas tentativas até que os avaliadores verificassem que estavam familiarizados com 0 equipamento e o procedimento de coleta.

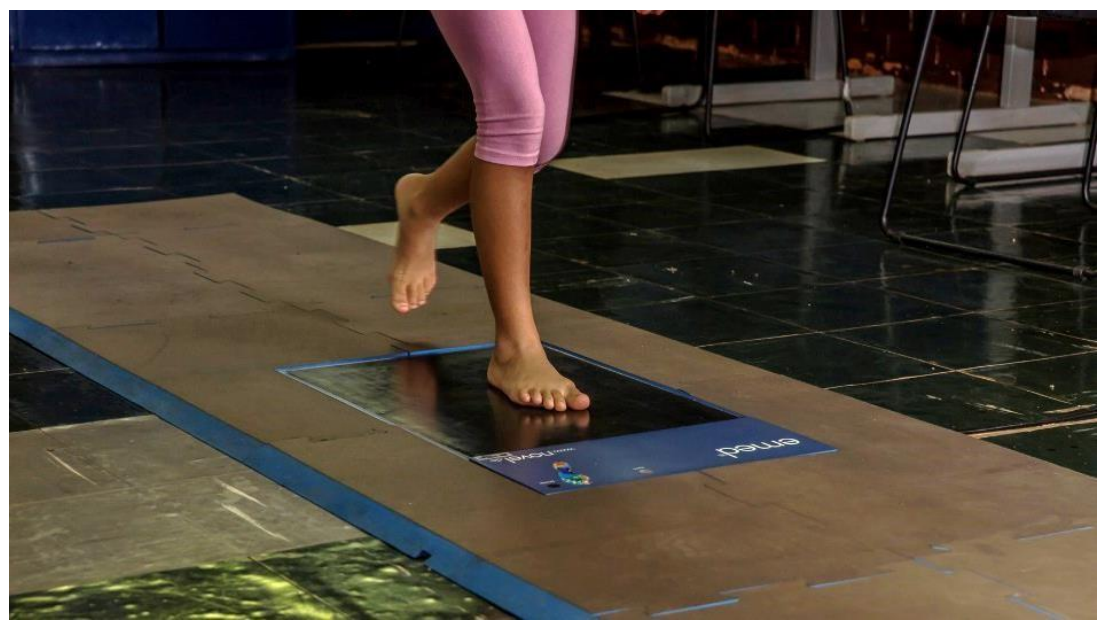

Figura 3. Plataforma Emed-n50®, Novel, Alemanha (Autor: Antônio Mesquita)

As crianças foram orientadas a se deslocar em velocidade auto selecionada, olhando para frente, tendo como referência um dos avaliadores posicionado ao fim do percurso, com o objetivo de evitar o efeito alvo na plataforma. Os avaliadores foram responsáveis por ajustar a posição de início do movimento para que a tentativa fosse válida e realizada com o membro desejado. As tentativas foram validadas quando o pé entrou em contato com a plataforma sem exceder a região contendo sensores. $O$ deslocamento foi realizado em velocidade auto selecionada, visto que estudos com crianças entre 1 e 10 anos de idade indicaram que o padrão da marcha é alterado quando a velocidade é pré-determinada (44). Foram registradas cinco tentativas válidas para cada pé durante o andar e também durante o correr para assegurar confiabilidade (45).

\subsubsection{Classificação do Índice de massa corpórea (IMC)}

O índice de massa corpórea varia muito durante a infância, por isso Cole et al (43) determinaram pontos de corte para cada idade, estabelecendo parâmetros para comparação do IMC de crianças.

Todos os participantes tiveram seus índices calculados a partir da seguinte fórmula: 


$$
\mathrm{IMC}=\frac{\text { Inassa }}{(\text { altura } \cdot \text { altura })}
$$

O corte de Cole et al (43) foi utilizado como referência para classificação dos sujeitos como eutróficos, com sobrepeso ou obesidade de acordo com os valores da Tabela 1 .

Tabela 1. Valores de referência do corte de Cole et al para classificação de crianças de acordo com o IMC

\begin{tabular}{lccccc} 
& \multicolumn{2}{c}{ IMC $\mathbf{2 5} \mathbf{~ K g} / \mathbf{m}^{\mathbf{2}}$} & & \multicolumn{2}{c}{ IMC $\mathbf{3 0 ~} \mathbf{~ K g} / \mathbf{m}^{\mathbf{2}}$} \\
\cline { 2 - 3 } \cline { 5 - 6 } Idade (anos) & Masculino & Feminino & & Masculino & Feminino \\
\hline 4 & 17.55 & 17.28 & & 19.29 & 19.15 \\
\hline 4.5 & 17.47 & 17.19 & & 19.26 & 19.12 \\
\hline 5 & 17.42 & 17.15 & & 19.30 & 19.17 \\
\hline 5.5 & 17.45 & 17.20 & & 19.47 & 19.34 \\
\hline 6 & 17.55 & 17.34 & & 19.78 & 19.65 \\
\hline 6.5 & 17.71 & 17.53 & 20.23 & 20.08 \\
\hline 7 & 17.92 & 17.75 & 20.63 & 20.51 \\
\hline 7.5 & 18.16 & 18.03 & 21.09 & 21.01 \\
\hline 8 & 18.44 & 18.35 & 21.60 & 21.57 \\
\hline 8.5 & 18.76 & 18.69 & 22.17 & 22.18 \\
\hline 9 & 19.10 & 19.07 & & 22.77 & 22.81 \\
\hline 9.5 & 19.46 & 19.45 & 23.39 & 23.46 \\
\hline 10 & 19.84 & 19.86 & 24.00 & 24.11 \\
\hline 10.5 & 20.20 & 20.29 & 24.57 & 24.77 \\
\hline
\end{tabular}

Os dados da Tabela 1 indicam os pontos de corte de valores do IMC para que a criança seja classificada como com sobrepeso (IMC $25 \mathrm{Kg} / \mathrm{m}^{2}$ ) ou obesa (IMC $30 \mathrm{Kg} / \mathrm{m}^{2}$ ), as crianças eutróficas são aquelas que possuem valor de IMC menor que o da coluna IMC $25 \mathrm{Kg} / \mathrm{m}^{2}$.

\subsubsection{Classificação do índice do arco plantar (IAP)}

A medida do índice do arco plantar é uma forma indireta, capaz de predizer e quantificar o desenvolvimento do arco longitudinal medial (46). Segundo o método criado por Cavanagh e Rodgers (46), é possível calcular o índice do arco a partir de impressões plantares estáticas ou dinâmicas, dependendo do tipo de índice que se deseja obter. As diferenças entre os dois tipos de medidas se destacam pelo fato de que o stress gerado durante uma aquisição dinâmica é maior, podendo causar variações na altura do arco plantar. Além disso, os autores destacam que as características do sistema musculoesquelético de cada sujeito também podem apresentar respostas diferentes durante as atividades, sendo assim importante que 
sejam controladas as condições biomecânicas durante a coleta das impressões plantares.

Para a realização do cálculo, devem ser realizadas algumas marcações em uma impressão plantar (Figura 4). Primeiramente deve-se traçar a linha do eixo do pé $(L)$ que une os pontos $J$ - na base do segundo dedo e $\mathrm{K}$ - no centro do calcanhar previamente demarcados. Em seguida, uma linha perpendicular a esta é traçada na parte mais anterior do pé, desconsiderando os dedos. A linha do eixo do pé deve então ser dividida em 3 partes iguais: calcanhar (A), mediopé (B) e antepé (C).
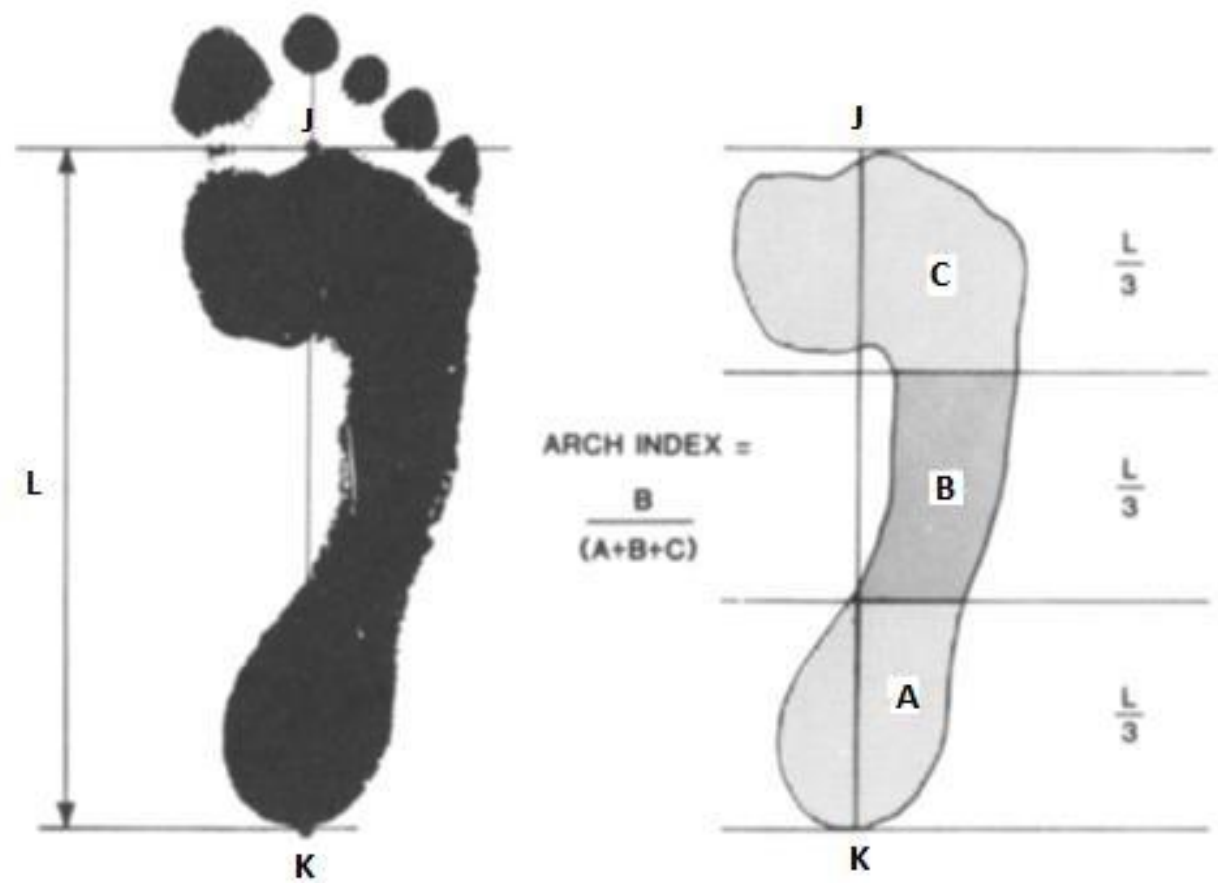

Figura 4. Representação das marcações na impressão plantar para cálculo do IAP. (Fonte: Cavanagh e Rodgers, 1987)

Após feitas as marcações, o índice do arco plantar pode ser calculado pela razão entre o comprimento de $\mathrm{B}$ e a soma de todos os terços, ou $\mathrm{o}$ comprimento de L. Com base na metodologia de Cavanagh e Rodgers, neste estudo foi utilizada a medida da área de contato absoluta disponibilizada pelo software para realização do cálculo do IAP. 
Tabela 2. Valores de referência para classificação do arco longitudinal plantar.

\begin{tabular}{|l|c|}
\hline Arco Alto & $\mathrm{Al} \leq 0,21$ \\
\hline Arco Normal & $0,21<\mathrm{Al}<0,26$ \\
\hline Arco Baixo & $\mathrm{Al} \geq 0,26$ \\
\hline
\end{tabular}

Quanto maior o valor obtido para o IAP, menor é a sua altura, ou seja, maior é a área de contato da região medial do pé com o solo. Os valores de referência foram definidos no estudo de Cavanagh e Rodgers (46) e estão descritos na Tabela 2.
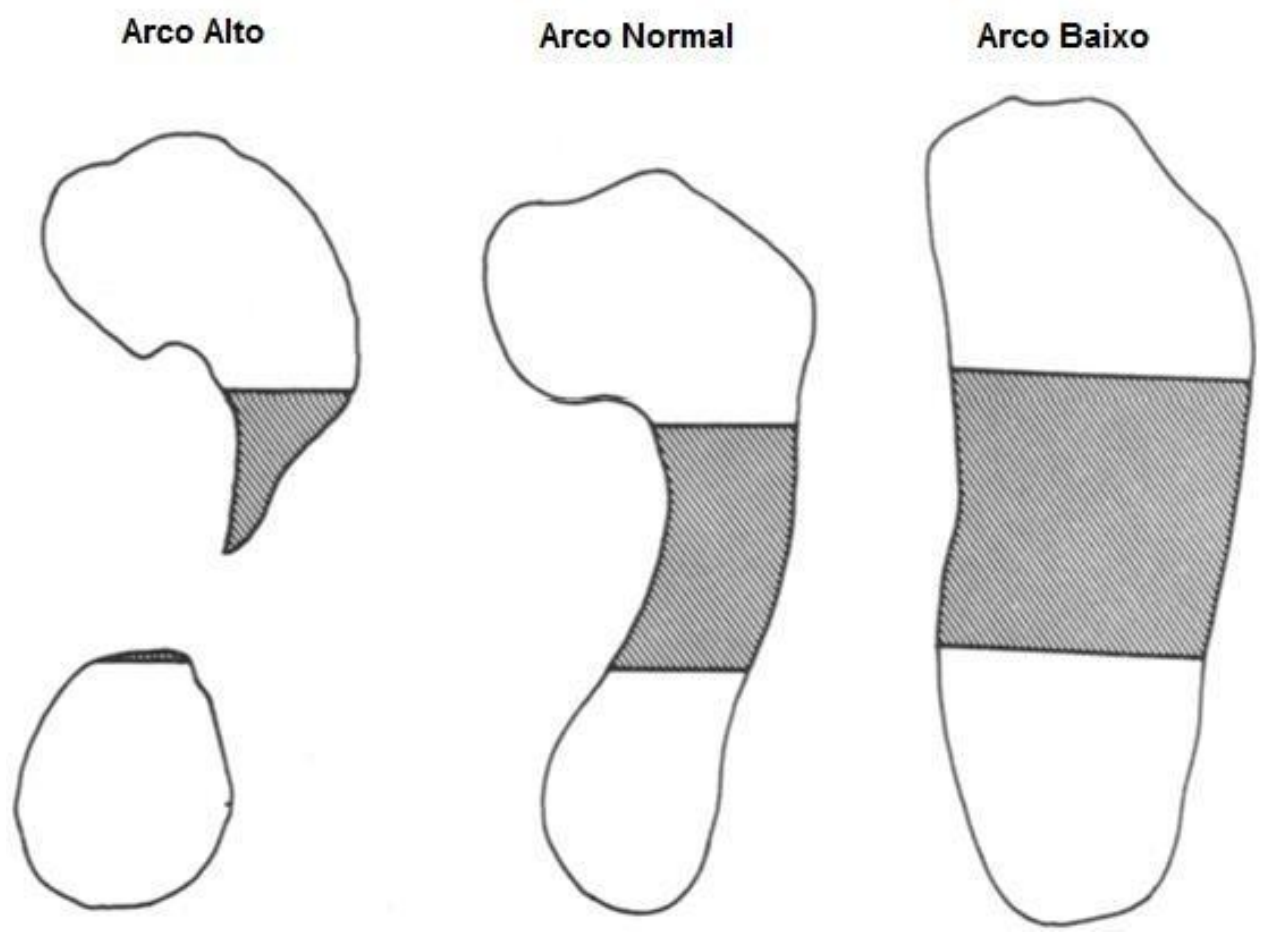

Figura 5. Representação dos tipos de classificação do arco plantar. (Fonte: Cavanagh e Rodgers, 1987)

A partir dos valores obtidos para o IAP é possível classificar o arco plantar em três categorias, ilustradas na Figura 5: pé cavo (arco alto), pé normal ou pé plano (arco baixo).

\subsection{Processamento de dados}

Após as coletas, todos os dados foram armazenados em uma base de dados no software Emed/R - Database Light 23.3.44. Antes do início do processamento, as tentativas foram analisadas para seleção daquelas que seriam utilizadas, verificando a necessidade de edições, como, por exemplo, rotacionar uma imagem em que o pé tenha ficado em direção diferente. Foram 
consideradas para análise apenas as tentativas em que houve contato da região do calcanhar com o solo.

Em seguida, as tentativas foram processadas individualmente no software HMFT, que identificou por meio de porcentagens na impressão plantar 05 áreas plantares específicas (máscaras) a serem analisadas, além da área total do pé. Esse número de divisões foi considerado adequado devido ao tamanho reduzido do pé das crianças e da resolução espacial da plataforma (5). O software calcula automaticamente as máscaras utilizadas na divisão do pé, conforme apresentado na Figura 6 . Considerando $0 \%$ como a extremidade do calcanhar e 100\% como a extremidade dos dedos, a divisão das regiões se dá da seguinte forma: o calcanhar (1) corresponde à área entre 0\% e 30\%, o mediopé (2), entre $30 \%$ e $60 \%$ e o antepé (3) entre $60 \%$ e $80 \%$. O hálux (4) e os dedos (5) ocupam a região entre $80 \%$ e $100 \%$ sendo que o hálux corresponde à porção de $0 \%$ a $33 \%$ da largura dessa região e os dedos de $33 \%$ a $100 \%$, considerando como $0 \%$ a região mais medial do pé e $100 \%$ a parte lateral.

Após esta etapa, foram gerados relatórios, identificados com os dados do sujeito e a tentativa que foi analisada, que disponibilizam em forma de gráfico e tabela os valores das variáveis plantares em cada uma das máscaras e na área total do pé (Anexo II). As variáveis dependentes analisadas neste estudo foram: (1) tempo de contato relativo (TC\%) - em porcentagem do tempo total de apoio no solo, (2) pico de pressão (PP) - maior valor de pressão registrado nas áreas plantares específicas em $\mathrm{kPa}$, (3) força máxima (FMáx) maior valor de força registrado nas áreas plantares específicas em N, (4) força máxima normalizada (FMáx\%) - maior valor de força, normalizado pelo peso corporal registrado nas áreas plantares específicas, (5) área de contato (AC) - área de contato do pé com o solo em $\mathrm{cm}^{2} \mathrm{e} \mathrm{(6)} \mathrm{área} \mathrm{de} \mathrm{contato} \mathrm{relativa}$ $(\mathrm{AC} \%)$ - área de contato com o solo em porcentagem da área total de contato. 


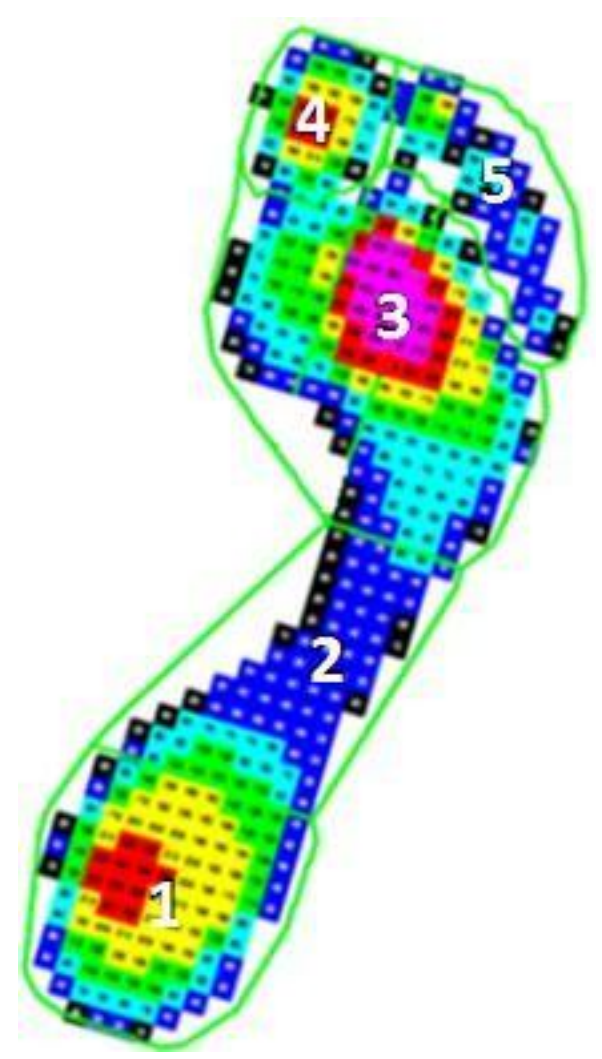

Figura 6. Imagem gerada pelo software Automask Emed/R da divisão do pé em 5 regiões (Novel, Alemanha)

Por fim, os dados foram tabulados em planilhas do Excel, onde foi calculada a média das 5 tentativas selecionadas para cada pé e em cada movimento, para que fossem criados os bancos de dados para análise estatística.

\subsection{Procedimentos de análise estatística}

A análise estatística foi realizada utilizando o pacote de dados SPSS versão 22.0 para Windows.

Inicialmente, os dados foram submetidos a uma análise descritiva, com medidas de tendência central e dispersão, para limpeza do banco de dados quanto a valores extremos e outliers. O pressuposto de normalidade foi verificado por meio do teste de Kolmogorov-Smirnov para todas as variáveis, em cada faixa etária e em cada uma das regiões analisadas.

Foi utilizado o Teste-t para amostras pareadas para que fossem verificadas as diferenças entre o pé esquerdo e o pé direito e, ainda, para comparar o andar e o correr nas variáveis de distribuição da pressão plantar em cada região do pé analisada. A correlação das variáveis de pressão plantar com a idade e com as variáveis morfológicas foi verificada pelo coeficiente de 
Pearson. Para estimar os tamanhos de efeito entre as correlações utilizou-se os valores de referência estabelecidos por Cohen, a saber: $r=0,10$ (efeito pequeno), $r=0,30$ (efeito médio), $r=0,50$ (efeito grande) (47). $O$ nível de significância adotado para todos os testes foi de $5 \%$.

\subsection{Limitações}

O estudo tem como principal limitação a não medição da velocidade do andar e correr dos participantes, que não foi realizada devido à falta de equipamentos adequados. É sabido que o padrão de movimento das crianças pode ser alterado quando a velocidade é previamente determinada (44), entretanto a velocidade é um fator que pode influenciar os padrões da distribuição da pressão plantar $(14,17,18)$, por isso sua descrição pode ser importante para que seus efeitos sobre as variáveis medidas possam ser verificados.

Outro fator limitante da pesquisa é a não utilização da análise cinemática. Esse instrumento poderia facilitar a análise dos padrões de movimento, principalmente do pé, contribuindo para a explicação dos resultados obtidos.

A resolução da plataforma também representa uma limitação para o estudo. Devido ao tamanho do pé das crianças, o número de sensores em contato com a área do pé é pequeno, impossibilitando sua divisão em um número maior de regiões para análise. A frequência de amostragem de 50 hertz $(\mathrm{Hz})$ também pode ser limitante para a análise da corrida, uma vez que o movimento pode vir a acontecer em frequências mais altas, resultando em perda de dados. 


\section{RESULTADOS}

O estudo teve como um de seus objetivos, descrever as variáveis de pressão plantar durante o andar e o correr para cada idade. Os resultados apresentados nesta seção mostram o comportamento da distribuição da pressão plantar ao longo da faixa etária de 4 a 10 anos, comparando os valores obtidos para o andar e o correr. Não foram encontradas diferenças significativas entre os pés esquerdo e direito, dessa forma os resultados apresentados referem-se aos dados do pé direito.

\subsection{Pressão plantar entre $o$ andar e o correr}

A Tabela 3 apresenta a caracterização dos sujeitos participantes do estudo. Os valores de peso e estatura apresentaram crescimentos contínuos de $120 \%$ e $36 \%$, respectivamente. O comprimento do pé (CP) aumentou cerca de $10 \mathrm{~mm}$ a cada ano e o IMC também sofreu acréscimos com o aumento da idade. Já o índice do arco plantar apresentou uma tendência a valores menores com o crescimento das crianças.

Tabela 3. Dados antropométricos dos participantes do estudo.

\begin{tabular}{cccccccc}
\hline \multicolumn{7}{c}{ DADOS ANTROPOMÉTRICOS } \\
\hline & $\begin{array}{c}\mathbf{4} \text { anos } \\
(\mathbf{n = 1 3})\end{array}$ & $\begin{array}{c}\mathbf{5} \text { anos } \\
(\mathbf{n = 1 7})\end{array}$ & $\begin{array}{c}\mathbf{6} \text { anos } \\
(\mathbf{n = 1 2})\end{array}$ & $\begin{array}{c}\mathbf{7} \text { anos } \\
(\mathbf{n = 1 5})\end{array}$ & $\begin{array}{c}\mathbf{8} \text { anos } \\
(\mathbf{n = 1 3})\end{array}$ & $\begin{array}{c}\mathbf{9} \text { anos } \\
(\mathbf{n = 1 7})\end{array}$ & $\begin{array}{c}\mathbf{1 0} \text { anos } \\
(\mathbf{n = 1 6})\end{array}$ \\
\hline $\begin{array}{c}\text { Idade } \\
\text { (anos) }\end{array}$ & $4,30 \pm 0,16$ & $5,50 \pm 0,28$ & $6,26 \pm 0,27$ & $7,33 \pm 0,26$ & $8,35 \pm 0,29$ & $9,47 \pm 0,22$ & $10,56 \pm 0,41$ \\
\hline $\begin{array}{c}\text { Peso } \\
\text { (Kg) }\end{array}$ & $16,09 \pm 1,24$ & $19,62 \pm 1,87$ & $22,62 \pm 3,08$ & $23,93 \pm 2,87$ & $26,53 \pm 4,81$ & $29,34 \pm 3,48$ & $35,44 \pm 5,56$ \\
\hline $\begin{array}{c}\text { Estatura } \\
(\mathbf{c m})\end{array}$ & $105,31 \pm 4,12$ & $114,85 \pm 3,64$ & $121,63 \pm 5,75$ & $125,17 \pm 5,15$ & $130,12 \pm 7,45$ & $136,25 \pm 5,08$ & $143,41 \pm 6,25$ \\
\hline $\begin{array}{c}\text { CP } \\
(\mathbf{c m})\end{array}$ & $17,08 \pm 0,58$ & $19,04 \pm 0,91$ & $19,94 \pm 1,11$ & $20,35 \pm 0,99$ & $21,49 \pm 1,49$ & $22,03 \pm 0,97$ & $23,19 \pm 1,12$ \\
\hline IMC & $14,54 \pm 1,21$ & $14,85 \pm 1,02$ & $15,24 \pm 1,20$ & $15,25 \pm 1,31$ & $15,55 \pm 1,42$ & $15,77 \pm 1,45$ & $17,16 \pm 2,05$ \\
\hline IAP & $0,33 \pm 0,05$ & $0,26 \pm 0,07$ & $0,22 \pm 0,09$ & $0,26 \pm 0,05$ & $0,21 \pm 0,06$ & $0,20 \pm 0,08$ & $0,21 \pm 0,08$ \\
\hline $\begin{array}{c}\text { Classificação } \\
\text { IAP }\end{array}$ & Baixo & Baixo & Normal & Baixo & Alto & Alto & Alto \\
\hline
\end{tabular}

Legenda: CP - comprimento do pé/ IMC - índice de massa corpórea; IAP - índice do arco plantar

Os resultados referentes ao tempo de contato relativo estão apresentados na Tabela 4. Os valores de TC\% durante o andar se mostraram significativamente mais altos do que durante o correr para todos os grupos na região do calcanhar e para os grupos de 4 e 8 anos no mediopé. Nas regiões do hálux e dedos, os 
valores foram significativamente maiores durante o correr e no antepé não foram observadas diferenças significativas.

Tabela 4. Diferenças entre o andar e o correr para a variável tempo de contato relativo nas regiões de análise do pé $(p \leq 0,05)$.

\begin{tabular}{|c|c|c|c|c|c|c|c|}
\hline \multicolumn{8}{|c|}{ Tempo de Contato (\% Total) } \\
\hline & $\begin{array}{l}4 \text { anos } \\
(n=13)\end{array}$ & $\begin{array}{l}5 \text { anos } \\
(n=17)\end{array}$ & $\begin{array}{l}6 \text { anos } \\
(\mathrm{n}=12)\end{array}$ & $\begin{array}{l}7 \text { anos } \\
(n=15)\end{array}$ & $\begin{array}{l}8 \text { anos } \\
(n=13)\end{array}$ & $\begin{array}{l}9 \text { anos } \\
(\mathrm{n}=17)\end{array}$ & $\begin{array}{c}10 \text { anos } \\
(n=16)\end{array}$ \\
\hline \multicolumn{8}{|l|}{ Calcanhar } \\
\hline Andar & $48,62 \pm 7,57$ & $53,35 \pm 9,01$ & $55,36 \pm 7,33$ & $53,53 \pm 10,07$ & $54,62 \pm 7,15$ & $54,83 \pm 8,03$ & $51,52 \pm 9,00$ \\
\hline Correr & $42,07 \pm 9,66$ & $40,77 \pm 9,39$ & $36,47 \pm 8,48$ & $42,42 \pm 10,00$ & $38,69 \pm 5,74$ & $44,31 \pm 8,48$ & $41,59 \pm 13,46$ \\
\hline$p$ & $0,039 *$ & $0,000^{*}$ & $0,000 *$ & $0,000 *$ & $0,000 *$ & $0,001 *$ & $0,008^{*}$ \\
\hline \multicolumn{8}{|l|}{ Mediopé } \\
\hline Andar & $61,03 \pm 7,75$ & $60,77 \pm 8,33$ & $60,16 \pm 6,67$ & $59,30 \pm 7,45$ & $62,86 \pm 1,54$ & $59,91 \pm 9,14$ & $59,43 \pm 10,49$ \\
\hline Correr & $55,98 \pm 8,05$ & $60,42 \pm 6,49$ & $57,81 \pm 4,64$ & $58,48 \pm 11,33$ & $57,27 \pm 4,88$ & $57,36 \pm 6,95$ & $58,04 \pm 8,08$ \\
\hline$p$ & $0,030 *$ & 0,852 & 0,262 & 0,783 & $0,006^{*}$ & 0,306 & 0,538 \\
\hline \multicolumn{8}{|l|}{ Antepé } \\
\hline Andar & $80,65 \pm 8,00$ & $81,98 \pm 3,65$ & $82,63 \pm 4,64$ & $82,75 \pm 3,78$ & $84,21 \pm 2,17$ & $82,94 \pm 3,70$ & $85,89 \pm 3,22$ \\
\hline Correr & $81,43 \pm 5,82$ & $82,62 \pm 4,45$ & $85,61 \pm 4,25$ & $85,50 \pm 6,12$ & $83,52 \pm 4,61$ & $81,41 \pm 6,52$ & $84,92 \pm 5,61$ \\
\hline$p$ & 0,718 & 0,515 & 0,079 & 0,090 & 0,730 & 0,399 & 0,473 \\
\hline \multicolumn{8}{|l|}{ Hálux } \\
\hline Andar & $71,29 \pm 13,51$ & $60,97 \pm 10,73$ & $57,75 \pm 9,16$ & $64,95 \pm 11,09$ & $62,71 \pm 10,86$ & $67,99 \pm 14,61$ & $67,64 \pm 12,50$ \\
\hline Correr & $80,87 \pm 7,68$ & $85,78 \pm 4,23$ & $84,42 \pm 6,43$ & $80,79 \pm 7,96$ & $82,60 \pm 5,22$ & $81,52 \pm 5,52$ & $81,62 \pm 4,93$ \\
\hline$p$ & $0,002 *$ & $0,000^{*}$ & $0,000 *$ & $0,000^{*}$ & $0,000^{*}$ & $0,003 *$ & $0,000^{*}$ \\
\hline \multicolumn{8}{|l|}{ Dedos } \\
\hline Andar & $70,08 \pm 13,32$ & $58,35 \pm 10,32$ & $66,09 \pm 6,04$ & $68,55 \pm 10,95$ & $72,91 \pm 5,94$ & $72,24 \pm 12,58$ & $75,13 \pm 9,95$ \\
\hline Correr & $82,27 \pm 7,46$ & $85,83 \pm 4,14$ & $87,55 \pm 4,25$ & $85,45 \pm 6,12$ & $86,25 \pm 3,59$ & $85,44 \pm 2,59$ & $85,93 \pm 4,94$ \\
\hline$p$ & $0,003^{*}$ & $0,000^{*}$ & $0,000 *$ & $0,000 *$ & $0,000 *$ & $0,001 *$ & $0,001 *$ \\
\hline
\end{tabular}

Durante o andar, é possível observar tendências de valores crescentes com a idade, com exceção do mediopé e hálux, onde os valores tendem a decrescer. Para o correr, a tendência é de que o TC\% diminua no calcanhar e aumente nas regiões do antepé e dedos.

Para o pico de pressão as diferenças foram significativas entre o correr e o andar, com cargas maiores durante o correr em todas as regiões analisadas, exceto o calcanhar (Tabela 5). É possível verificar que o PP tende a apresentar aumento dos valores com a idade. Esse comportamento pode ser identificado para ambos os movimentos na maior parte das regiões de análise, com exceção do mediopé e também do calcanhar, porém este último apenas durante o correr. Os maiores picos de pressão foram vistos, durante o andar, sob o calcanhar e, durante o correr, na região do hálux. 
Tabela 5. Diferenças entre o andar e o correr para a variável pico de pressão ( $\mathrm{kPa})$ nas regiões de análise do pé $(p \leq 0,05)$.

\begin{tabular}{|c|c|c|c|c|c|c|c|}
\hline \multicolumn{8}{|c|}{ Pico de Pressão (kPa) } \\
\hline & $\begin{array}{l}4 \text { anos } \\
(n=13)\end{array}$ & $\begin{array}{l}5 \text { anos } \\
(n=17)\end{array}$ & $\begin{array}{l}6 \text { anos } \\
(n=12)\end{array}$ & $\begin{array}{l}7 \text { anos } \\
(n=15)\end{array}$ & $\begin{array}{l}8 \text { anos } \\
(\mathrm{n}=13)\end{array}$ & $\begin{array}{l}9 \text { anos } \\
(\mathrm{n}=17)\end{array}$ & $\begin{array}{c}10 \text { anos } \\
(n=16)\end{array}$ \\
\hline \multicolumn{8}{|l|}{ Total } \\
\hline Andar & $359,15 \pm 101,10$ & $425,00 \pm 136,12$ & $389,67 \pm 83,35$ & $388,67 \pm 73,79$ & $379,08 \pm 69,58$ & $428,65 \pm 110,96$ & $438,33 \pm 154,36$ \\
\hline Correr & $432,62 \pm 103,73$ & $519,00 \pm 135,56$ & $464,25 \pm 95,97$ & $469,79 \pm 174,41$ & $569,47 \pm 178,61$ & $571,82 \pm 135,59$ & $628,13 \pm 254,09$ \\
\hline$p$ & 0,077 & $0,014 *$ & $0,020^{*}$ & 0,057 & $0,000^{*}$ & $0,000^{*}$ & $0,002^{*}$ \\
\hline \multicolumn{8}{|l|}{ Calcanhar } \\
\hline Andar & $337,15 \pm 107,48$ & $390,88 \pm 132,02$ & $366,50 \pm 95,07$ & $342,07 \pm 87,09$ & $342,15 \pm 85,89$ & $351,94 \pm 120,62$ & $351,06 \pm 133,09$ \\
\hline Correr & $391,54 \pm 120,50$ & $342,71 \pm 130,58$ & $292,00 \pm 124,38$ & $299,54 \pm 59,91$ & $388,64 \pm 167,93$ & $376,35 \pm 153,66$ & $311,00 \pm 159,16$ \\
\hline$p$ & 0,159 & 0,280 & 0,146 & 0,224 & 0,322 & 0,569 & 0,438 \\
\hline \multicolumn{8}{|l|}{ Mediopé } \\
\hline Andar & $88,85 \pm 15,04$ & $68,41 \pm 18,19$ & $70,08 \pm 18,85$ & $68,93 \pm 17,98$ & $66,77 \pm 23,21$ & $70,65 \pm 25,26$ & $76,56 \pm 33,84$ \\
\hline Correr & $117,23 \pm 23,30$ & $112,29 \pm 23,97$ & $104,17 \pm 28,66$ & $118,53 \pm 33,52$ & $134,22 \pm 35,12$ & $150,88 \pm 37,93$ & $139,50 \pm 57,11$ \\
\hline$p$ & $0,003 *$ & $0,000 *$ & $0,002 *$ & $0,000 *$ & $0,000 *$ & $0,000 *$ & $0,000 *$ \\
\hline \multicolumn{8}{|l|}{ Antepé } \\
\hline Andar & $169,85 \pm 46,86$ & $193,44 \pm 28,55$ & $197,18 \pm 21,62$ & $219,87 \pm 52,25$ & $235,62 \pm 53,11$ & $259,24 \pm 59,54$ & $277,86 \pm 31,27$ \\
\hline Correr & $180,54 \pm 49,56$ & $266,88 \pm 100,95$ & $326,50 \pm 96,82$ & $292,60 \pm 88,20$ & $313,25 \pm 43,35$ & $338,12 \pm 78,64$ & $413,63 \pm 150,40$ \\
\hline$p$ & 0,491 & $0,017 *$ & $0,001 *$ & $0,004 *$ & $0,001 *$ & $0,000 *$ & $0,004 *$ \\
\hline \multicolumn{8}{|l|}{ Hálux } \\
\hline Andar & $204,38 \pm 40,03$ & $276,88 \pm 88,36$ & $228,33 \pm 64,40$ & $229,87 \pm 87,37$ & $250,85 \pm 77,95$ & $314,18 \pm 101,38$ & $319,92 \pm 157,39$ \\
\hline Correr & $270,62 \pm 69,51$ & $350,18 \pm 114,55$ & $342,83 \pm 67,47$ & $353,00 \pm 204,13$ & $429,94 \pm 189,13$ & $445,71 \pm 178,95$ & $498,19 \pm 275,19$ \\
\hline$p$ & $0,008 *$ & $0,004 *$ & $0,001 *$ & $0,010^{*}$ & $0,002 *$ & $0,001 *$ & $0,001 *$ \\
\hline \multicolumn{8}{|l|}{ Dedos } \\
\hline Andar & $153,92 \pm 47,42$ & $144,76 \pm 23,63$ & $172,00 \pm 42,10$ & $178,33 \pm 47,54$ & $190,38 \pm 45,68$ & $183,12 \pm 44,56$ & $220,98 \pm 50,03$ \\
\hline Correr & $168,46 \pm 52,91$ & $196,47 \pm 56,91$ & $268,33 \pm 93,50$ & $216,87 \pm 55,13$ & $245,36 \pm 59,89$ & $232,82 \pm 52,20$ & $299,06 \pm 103,49$ \\
\hline$p$ & 0,364 & $0,002 *$ & $0,001 *$ & $0,014 *$ & $0,001 *$ & $0,000^{*}$ & $0,002 *$ \\
\hline
\end{tabular}


Tabela 6. Diferenças entre o andar e o correr para a variável força máxima $(\mathrm{N})$ nas regiões de análise do pé $(p \leq 0,05)$.

\begin{tabular}{|c|c|c|c|c|c|c|c|}
\hline \multicolumn{8}{|c|}{ Força Máxima (N) } \\
\hline & $\begin{array}{l}4 \text { anos } \\
(n=13)\end{array}$ & $\begin{array}{l}5 \text { anos } \\
(n=17)\end{array}$ & $\begin{array}{l}6 \text { anos } \\
(n=12)\end{array}$ & $\begin{array}{l}7 \text { anos } \\
(n=15)\end{array}$ & $\begin{array}{l}8 \text { anos } \\
(\mathrm{n}=13)\end{array}$ & $\begin{array}{l}9 \text { anos } \\
(n=17)\end{array}$ & $\begin{array}{c}10 \text { anos } \\
(n=16)\end{array}$ \\
\hline \multicolumn{8}{|l|}{ Total } \\
\hline Andar & $242,55 \pm 47,43$ & $250,70 \pm 27,30$ & $286,23 \pm 39,74$ & $298,16 \pm 37,06$ & $341,14 \pm 51,32$ & $375,74 \pm 44,84$ & $411,44 \pm 58,36$ \\
\hline Correr & $343,55 \pm 51,63$ & $453,21 \pm 71,03$ & $542,27 \pm 81,01$ & $548,59 \pm 64,03$ & $636,11 \pm 96,11$ & $699,35 \pm 58,86$ & $852,81 \pm 201,00$ \\
\hline$p$ & $0,000^{*}$ & $0,000 *$ & $0,000 *$ & $0,000^{*}$ & $0,000 *$ & $0,000 *$ & $0,000^{*}$ \\
\hline \multicolumn{8}{|c|}{ Calcanhar } \\
\hline Andar & $165,13 \pm 28,45$ & $196,15 \pm 28,05$ & $223,15 \pm 33,15$ & $219,05 \pm 18,83$ & $264,77 \pm 47,61$ & $281,28 \pm 36,53$ & $310,78 \pm 24,26$ \\
\hline Correr & $196,03 \pm 37,56$ & $210,49 \pm 50,41$ & $219,28 \pm 95,14$ & $263,64 \pm 85,71$ & $288,24 \pm 70,59$ & $311,52 \pm 58,45$ & $309,88 \pm 87,80$ \\
\hline$p$ & $0,034 *$ & 0,237 & 0,894 & 0,174 & 0,267 & 0,091 & 0,653 \\
\hline \multicolumn{8}{|l|}{ Mediopé } \\
\hline Andar & $73,13 \pm 32,65$ & $41,50 \pm 16,23$ & $40,66 \pm 23,33$ & $52,19 \pm 23,51$ & $40,76 \pm 20,55$ & $35,86 \pm 16,15$ & $63,15 \pm 46,72$ \\
\hline Correr & $121,50 \pm 52,50$ & $124,86 \pm 45,83$ & $111,62 \pm 63,66$ & $128,15 \pm 48,51$ & $123,41 \pm 53,57$ & $132,30 \pm 49,27$ & $130,46 \pm 62,75$ \\
\hline$p$ & $0,002 *$ & $0,000^{*}$ & $0,000 *$ & $0,000^{*}$ & $0,000^{*}$ & $0,000^{*}$ & $0,000 *$ \\
\hline \multicolumn{8}{|l|}{ Antepé } \\
\hline Andar & $124,19 \pm 31,86$ & $146,01 \pm 29,85$ & $185,48 \pm 23,40$ & $191,43 \pm 20,77$ & $232,07 \pm 52,79$ & $228,50 \pm 45,21$ & $284,52 \pm 61,84$ \\
\hline Correr & $160,67 \pm 18,43$ & $254,54 \pm 51,60$ & $346,91 \pm 60,42$ & $336,36 \pm 71,30$ & $402,80 \pm 75,12$ & $421,48 \pm 62,90$ & $552,45 \pm 159,82$ \\
\hline$p$ & $0,007 *$ & $0,000 *$ & $0,000 *$ & $0,000 *$ & $0,000 *$ & $0,000 *$ & $0,000 *$ \\
\hline \multicolumn{8}{|l|}{ Hálux } \\
\hline Andar & $44,12 \pm 9,95$ & $63,56 \pm 13,46$ & $60,08 \pm 12,87$ & $66,19 \pm 19,81$ & $79,49 \pm 22,99$ & $97,71 \pm 26,90$ & $95,25 \pm 32,21$ \\
\hline Correr & $58,75 \pm 16,18$ & $80,55 \pm 15,84$ & $97,48 \pm 20,90$ & $94,12 \pm 29,36$ & $120,73 \pm 34,74$ & $124,62 \pm 34,58$ & $142,22 \pm 51,65$ \\
\hline$p$ & $0,025^{*}$ & $0,000 *$ & $0,000 *$ & $0,000 *$ & $0,000 *$ & $0,000 *$ & $0,000 *$ \\
\hline \multicolumn{8}{|l|}{ Dedos } \\
\hline Andar & $37,52 \pm 15,57$ & $34,28 \pm 6,86$ & $44,50 \pm 14,47$ & $47,06 \pm 14,61$ & $50,85 \pm 9,54$ & $54,49 \pm 18,09$ & $60,11 \pm 13,56$ \\
\hline Correr & $44,02 \pm 14,11$ & $40,27 \pm 11,06$ & $65,87 \pm 12,98$ & $59,49 \pm 16,01$ & $66,14 \pm 19,63$ & $66,84 \pm 18,75$ & $78,96 \pm 18,06$ \\
\hline$p$ & 0,171 & $0,001^{*}$ & $0,000^{*}$ & $0,012 *$ & $0,006^{*}$ & $0,000 *$ & $0,000 *$ \\
\hline
\end{tabular}


A Tabela 6 apresenta os resultados referentes à força máxima absoluta. As diferenças significativas entre os movimentos, revelaram cargas maiores para o correr em relação ao andar para todos os grupos nas regiões total, mediopé, antepé e hálux. Apenas o grupo de 4 anos apresentou valores significativos para a comparação na região do calcanhar, enquanto que nos dedos, este foi o único grupo em que a diferença não foi significativa. Houve tendência de aumento da variável nas regiões de análise do pé ao longo das idades, tanto para o andar quanto para o correr. Apenas o mediopé apresentou tendência a valores menores com o aumento da idade, durante $o$ andar. As regiões com os maiores valores de Fmáx foram o calcanhar, durante o andar e o antepé, durante o correr.

A força máxima relativa tem seus valores descritos na Tabela 7. O correr apresentou valores significativamente mais altos que $\mathrm{o}$ andar em todas as regiões. As diferenças entre os movimentos foram significativas em todos os grupos na área total do pé e nas regiões do mediopé, antepé e hálux. Os grupos de 4 e 7 anos foram os únicos a apresentar valores significativos na região do calcanhar, enquanto nos dedos, o grupo de 4 anos foi o único em que a diferença não foi significativa. Com o aumento da idade, a tendência durante $o$ andar e o correr foi de que os valores fossem reduzidos nas regiões do calcanhar, mediopé e dedos, e aumentados no antepé e no hálux. $\mathrm{Na}$ área total do pé, a tendência foi de que a Fmáx\% fosse diminuída durante o andar e aumentada durante o correr. Os maiores valores também foram obtidos sob o calcanhar durante o andar e o antepé durante o correr. 
Tabela 7. Diferenças entre o andar e o correr para a variável força máxima relativa nas regiões de análise do pé $(p \leq 0,05)$.

\begin{tabular}{|c|c|c|c|c|c|c|c|}
\hline \multicolumn{8}{|c|}{ Força Máxima (\%PC) } \\
\hline & $\begin{array}{l}4 \text { anos } \\
(n=13)\end{array}$ & $\begin{array}{l}5 \text { anos } \\
(n=17)\end{array}$ & $\begin{array}{l}6 \text { anos } \\
(n=12)\end{array}$ & $\begin{array}{l}7 \text { anos } \\
(n=15)\end{array}$ & $\begin{array}{l}8 \text { anos } \\
(n=13)\end{array}$ & $\begin{array}{l}9 \text { anos } \\
(n=17)\end{array}$ & $\begin{array}{c}10 \text { anos } \\
(n=16)\end{array}$ \\
\hline \multicolumn{8}{|l|}{ Total } \\
\hline Andar & $155,95 \pm 34,74$ & $130,69 \pm 12,36$ & $129,51 \pm 12,42$ & $125,90 \pm 7,30$ & $131,64 \pm 9,57$ & $129,22 \pm 12,21$ & $118,27 \pm 4,11$ \\
\hline Correr & $222,82 \pm 29,24$ & $234,68 \pm 26,17$ & $243,53 \pm 24,71$ & $234,69 \pm 20,20$ & $247,21 \pm 29,32$ & $240,05 \pm 15,65$ & $247,77 \pm 31,78$ \\
\hline$p$ & $0,000^{*}$ & $0,000 *$ & $0,000 *$ & $0,000^{*}$ & $0,000^{*}$ & $0,000 *$ & $0,000^{*}$ \\
\hline \multicolumn{8}{|c|}{ Calcanhar } \\
\hline Andar & $105,14 \pm 19,18$ & $102,28 \pm 13,67$ & $101,96 \pm 12,43$ & $96,14 \pm 12,70$ & $102,08 \pm 8,39$ & $98,48 \pm 13,00$ & $89,61 \pm 7,02$ \\
\hline Correr & $124,79 \pm 22,58$ & $113,79 \pm 32,81$ & $98,56 \pm 40,79$ & $110,74 \pm 13,88$ & $117,96 \pm 35,69$ & $107,98 \pm 19,05$ & $90,09 \pm 30,31$ \\
\hline$p$ & $0,024 *$ & 0,145 & 0,797 & $0,041^{*}$ & 0,134 & 0,169 & 0,935 \\
\hline \multicolumn{8}{|l|}{ Mediopé } \\
\hline Andar & $40,00 \pm 11,51$ & $22,71 \pm 10,16$ & $19,29 \pm 8,29$ & $21,93 \pm 8,73$ & $17,63 \pm 11,31$ & $14,83 \pm 8,23$ & $17,02 \pm 11,20$ \\
\hline Correr & $77,55 \pm 32,38$ & $66,30 \pm 25,32$ & $50,10 \pm 24,86$ & $55,59 \pm 21,97$ & $49,31 \pm 23,39$ & $49,45 \pm 23,52$ & $41,95 \pm 26,93$ \\
\hline$p$ & $0,000^{*}$ & $0,000^{*}$ & $0,000^{*}$ & $0,000^{*}$ & $0,000^{*}$ & $0,000^{*}$ & $0,000^{*}$ \\
\hline \multicolumn{8}{|l|}{ Antepé } \\
\hline Andar & $75,92 \pm 13,90$ & $75,55 \pm 12,23$ & $83,14 \pm 7,25$ & $80,24 \pm 6,39$ & $89,15 \pm 11,78$ & $78,88 \pm 9,85$ & $80,51 \pm 11,47$ \\
\hline Correr & $109,87 \pm 25,00$ & $132,45 \pm 22,40$ & $157,31 \pm 24,73$ & $142,25 \pm 30,99$ & $156,07 \pm 20,87$ & $143,85 \pm 20,15$ & $156,53 \pm 35,23$ \\
\hline$p$ & $0,001^{*}$ & $0,000^{*}$ & $0,000^{*}$ & $0,000^{*}$ & $0,000^{*}$ & $0,000^{*}$ & $0,000^{*}$ \\
\hline \multicolumn{8}{|l|}{ Hálux } \\
\hline Andar & $28,06 \pm 6,50$ & $33,07 \pm 6,51$ & $27,85 \pm 7,27$ & $28,48 \pm 9,03$ & $30,84 \pm 8,31$ & $34,52 \pm 10,36$ & $27,22 \pm 8,96$ \\
\hline Correr & $37,95 \pm 10,80$ & $42,03 \pm 8,25$ & $44,10 \pm 8,21$ & $39,96 \pm 11,97$ & $47,77 \pm 12,39$ & $43,50 \pm 11,45$ & $39,86 \pm 12,73$ \\
\hline$p$ & $0,017^{*}$ & $0,000^{*}$ & $0,000^{*}$ & $0,000^{*}$ & $0,000^{*}$ & $0,000^{*}$ & $0,000^{*}$ \\
\hline \multicolumn{8}{|l|}{ Dedos } \\
\hline Andar & $23,71 \pm 9,79$ & $17,92 \pm 3,64$ & $20,18 \pm 6,38$ & $19,98 \pm 5,25$ & $19,79 \pm 4,55$ & $19,42 \pm 5,65$ & $17,32 \pm 4,22$ \\
\hline Correr & $28,40 \pm 9,34$ & $24,23 \pm 5,72$ & $28,12 \pm 7,15$ & $25,52 \pm 6,80$ & $24,67 \pm 4,77$ & $23,16 \pm 5,90$ & $23,09 \pm 6,30$ \\
\hline$p$ & 0,105 & $0,001^{*}$ & $0,001^{*}$ & $0,012 *$ & $0,002 *$ & $0,001 *$ & $0,000^{*}$ \\
\hline
\end{tabular}


Os resultados da Tabela 8 demonstram que a área de contato do pé foi significativamente maior durante o correr nas regiões analisadas, com exceção do calcanhar que apresentou tendência a valores mais altos durante o andar.

Tabela 8. Diferenças entre o andar e o correr para a variável área de contato $\left(\mathrm{cm}^{2}\right)$ nas regiões de análise do pé $(p \leq 0,05)$.

\begin{tabular}{|c|c|c|c|c|c|c|c|}
\hline \multicolumn{8}{|c|}{ Área de Contato $\left(\mathrm{cm}^{2}\right)$} \\
\hline & $\begin{array}{l}4 \text { anos } \\
(n=13)\end{array}$ & $\begin{array}{l}5 \text { anos } \\
(n=17)\end{array}$ & $\begin{array}{l}6 \text { anos } \\
(n=12)\end{array}$ & $\begin{array}{c}7 \text { anos } \\
(n=15)\end{array}$ & $\begin{array}{l}8 \text { anos } \\
(n=13)\end{array}$ & $\begin{array}{l}9 \text { anos } \\
(n=17)\end{array}$ & $\begin{array}{c}10 \text { anos } \\
(n=16)\end{array}$ \\
\hline \multicolumn{8}{|l|}{ Total } \\
\hline Andar & $66,85 \pm 7,11$ & $70,35 \pm 6,42$ & $72,97 \pm 11,05$ & $79,82 \pm 8,97$ & $80,89 \pm 9,23$ & $84,01 \pm 9,99$ & $93,22 \pm 12,20$ \\
\hline Correr & $69,52 \pm 8,30$ & $79,10 \pm 7,97$ & $80,56 \pm 11,42$ & $85,13 \pm 11,45$ & $89,55 \pm 9,34$ & $93,34 \pm 11,53$ & $97,55 \pm 16,57$ \\
\hline$p$ & 0,281 & $0,000 *$ & $0,000 *$ & 0,122 & $0,000 *$ & $0,000^{*}$ & 0,286 \\
\hline \multicolumn{8}{|c|}{ Calcanhar } \\
\hline Andar & $16,55 \pm 1,11$ & $19,32 \pm 1,86$ & $20,97 \pm 1,17$ & $22,08 \pm 1,67$ & $23,93 \pm 3,50$ & $24,98 \pm 2,26$ & $27,57 \pm 3,26$ \\
\hline Correr & $16,23 \pm 1,79$ & $18,31 \pm 2,58$ & $19,80 \pm 3,22$ & $21,70 \pm 2,05$ & $22,86 \pm 3,87$ & $23,92 \pm 2,82$ & $24,71 \pm 6,27$ \\
\hline$p$ & 0,424 & $0,029 *$ & $0,027 *$ & 0,702 & 0,166 & 0,060 & 0,068 \\
\hline \multicolumn{8}{|l|}{ Mediopé } \\
\hline Andar & $17,78 \pm 4,72$ & $15,02 \pm 4,25$ & $13,40 \pm 6,64$ & $16,79 \pm 4,20$ & $14,07 \pm 3,61$ & $13,96 \pm 4,72$ & $15,92 \pm 6,94$ \\
\hline Correr & $19,95 \pm 4,95$ & $22,75 \pm 4,82$ & $19,51 \pm 8,59$ & $20,72 \pm 6,01$ & $19,63 \pm 4,13$ & $20,74 \pm 6,87$ & $20,58 \pm 7,40$ \\
\hline$p$ & 0,090 & $0,000^{*}$ & $0,000^{*}$ & $0,015^{*}$ & $0,000 *$ & $0,000 *$ & $0,024 *$ \\
\hline \multicolumn{8}{|l|}{ Antepé } \\
\hline Andar & $19,33 \pm 1,81$ & $22,11 \pm 2,09$ & $23,61 \pm 2,29$ & $25,27 \pm 2,99$ & $26,18 \pm 3,51$ & $26,94 \pm 2,43$ & $31,03 \pm 3,56$ \\
\hline Correr & $19,98 \pm 0,35$ & $23,49 \pm 2,41$ & $24,92 \pm 0,62$ & $26,83 \pm 3,47$ & $29,50 \pm 3,33$ & $29,36 \pm 1,82$ & $33,38 \pm 3,83$ \\
\hline$p$ & 0,094 & $0,000^{*}$ & $0,000^{*}$ & $0,004 *$ & $0,000^{*}$ & $0,000^{*}$ & $0,000^{*}$ \\
\hline \multicolumn{8}{|l|}{ Hálux } \\
\hline Andar & $5,78 \pm 0,35$ & $6,84 \pm 0,40$ & $7,47 \pm 0,43$ & $7,72 \pm 0,58$ & $8,20 \pm 0,74$ & $8,84 \pm 0,80$ & $9,35 \pm 1,35$ \\
\hline Correr & $6,08 \pm 0,42$ & $6,96 \pm 0,38$ & $7,60 \pm 0,53$ & $7,81 \pm 1,01$ & $9,05 \pm 1,02$ & $9,02 \pm 0,65$ & $9,44 \pm 1,35$ \\
\hline$p$ & $0,019 *$ & 0,220 & 0,278 & 0,646 & $0,000 *$ & 0,155 & 0,668 \\
\hline \multicolumn{8}{|l|}{ Dedos } \\
\hline Andar & $7,26 \pm 1,72$ & $6,88 \pm 1,10$ & $7,62 \pm 1,58$ & $7,97 \pm 1,94$ & $8,54 \pm 1,04$ & $9,54 \pm 1,57$ & $9,67 \pm 1,16$ \\
\hline Correr & $7,68 \pm 1,26$ & $8,06 \pm 1,12$ & $9,11 \pm 1,15$ & $9,29 \pm 1,37$ & $9,43 \pm 1,28$ & $10,56 \pm 1,35$ & $10,96 \pm 1,33$ \\
\hline$p$ & 0,323 & $0,000^{*}$ & $0,000 *$ & $0,009 *$ & $0,018^{*}$ & $0,002 *$ & $0,000^{*}$ \\
\hline
\end{tabular}

A área total do pé apresentou valores significativos para os grupos de 5, 6, 8 e 9 anos e o calcanhar apenas para os grupos de 5 e 6 anos. Nas regiões do mediopé, antepé e dedos houve apenas o grupo de 4 anos não indicou diferenças significativas. Já o hálux obteve valores significativos apenas para os grupos de 4 e 8 anos. Todas as regiões analisadas, exceto o mediopé, apresentaram tendência de valores maiores com o aumento da idade. 
Tabela 9. Diferenças entre o andar e o correr na variável área de contato relativa nas regiões de análise do pé $(p \leq 0,05)$.

\begin{tabular}{|c|c|c|c|c|c|c|c|}
\hline \multicolumn{8}{|c|}{ Área de Contato (\% Total) } \\
\hline & $\begin{array}{l}4 \text { anos } \\
(n=13)\end{array}$ & $\begin{array}{l}5 \text { anos } \\
(\mathbf{n}=17) \\
\end{array}$ & $\begin{array}{l}6 \text { anos } \\
(n=12)\end{array}$ & $\begin{array}{l}7 \text { anos } \\
(n=15)\end{array}$ & $\begin{array}{l}8 \text { anos } \\
(n=13)\end{array}$ & $\begin{array}{l}9 \text { anos } \\
(n=17)\end{array}$ & $\begin{array}{c}10 \text { anos } \\
(n=16)\end{array}$ \\
\hline \multicolumn{8}{|c|}{ Calcanhar } \\
\hline Andar & $24,36 \pm 0,75$ & $25,57 \pm 2,37$ & $29,51 \pm 2,83$ & $27,75 \pm 3,01$ & $29,81 \pm 2,19$ & $29,82 \pm 1,93$ & $29,60 \pm 1,91$ \\
\hline Correr & $23,42 \pm 2,68$ & $22,91 \pm 1,50$ & $24,89 \pm 1,29$ & $24,75 \pm 2,48$ & $25,79 \pm 1,88$ & $25,34 \pm 1,35$ & $24,52 \pm 3,29$ \\
\hline$p$ & 0,150 & $0,000^{*}$ & $0,000^{*}$ & $0,001^{*}$ & $0,000^{*}$ & $0,000^{*}$ & $0,000^{*}$ \\
\hline \multicolumn{8}{|l|}{ Mediopé } \\
\hline Andar & $26,19 \pm 5,21$ & $21,29 \pm 5,27$ & $19,38 \pm 4,17$ & $20,74 \pm 3,96$ & $17,49 \pm 4,16$ & $16,34 \pm 4,07$ & $16,93 \pm 6,66$ \\
\hline Correr & $29,34 \pm 2,68$ & $28,52 \pm 4,18$ & $24,51 \pm 5,11$ & $24,08 \pm 6,55$ & $21,94 \pm 4,18$ & $22,19 \pm 4,47$ & $20,69 \pm 6,13$ \\
\hline$p$ & $0,007 *$ & $0,000 *$ & $0,000^{*}$ & $0,032 *$ & $0,000^{*}$ & $0,000^{*}$ & $0,009^{*}$ \\
\hline \multicolumn{8}{|l|}{ Antepé } \\
\hline Andar & $29,03 \pm 1,79$ & $31,55 \pm 2,23$ & $31,66 \pm 2,20$ & $31,83 \pm 1,74$ & $32,16 \pm 1,67$ & $32,30 \pm 3,00$ & $32,22 \pm 3,53$ \\
\hline Correr & $28,88 \pm 2,33$ & $28,72 \pm 2,67$ & $31,76 \pm 3,34$ & $32,60 \pm 9,43$ & $32,04 \pm 2,51$ & $32,05 \pm 3,45$ & $35,30 \pm 6,95$ \\
\hline$p$ & 0,792 & $0,001 *$ & 0,929 & 0,751 & 0,860 & 0,734 & 0,234 \\
\hline \multicolumn{8}{|l|}{ Hálux } \\
\hline Andar & $8,94 \pm 0,91$ & $9,55 \pm 0,26$ & $9,70 \pm 0,88$ & $9,78 \pm 0,84$ & $10,36 \pm 1,92$ & $10,57 \pm 0,71$ & $10,04 \pm 1,57$ \\
\hline Correr & $8,87 \pm 1,08$ & $8,84 \pm 0,87$ & $9,47 \pm 1,11$ & $9,32 \pm 1,56$ & $10,18 \pm 0,93$ & $9,89 \pm 0,77$ & $9,86 \pm 1,44$ \\
\hline$p$ & 0,797 & $0,001 *$ & 0,451 & 0,330 & 0,446 & $0,001 *$ & 0,657 \\
\hline \multicolumn{8}{|l|}{ Dedos } \\
\hline Andar & $10,90 \pm 2,53$ & $9,76 \pm 1,26$ & $10,50 \pm 2,00$ & $9,98 \pm 1,52$ & $10,54 \pm 1,32$ & $11,40 \pm 1,68$ & $10,32 \pm 1,29$ \\
\hline Correr & $11,13 \pm 2,11$ & $10,07 \pm 0,96$ & $11,00 \pm 1,60$ & $10,90 \pm 2,12$ & $10,53 \pm 1,61$ & $11,41 \pm 1,46$ & $11,51 \pm 2,83$ \\
\hline$P$ & 0,688 & 0,397 & 0,202 & $0,007 *$ & 0,970 & 0,962 & 0,080 \\
\hline
\end{tabular}

Os resultados da área de contato relativa estão representados na Tabela 9. As comparações entre $\mathrm{o}$ andar e o correr indicaram diferenças significativas, com áreas maiores durante o andar no calcanhar, antepé e hálux, e durante o correr para mediopé e dedos. Com o aumento da idade, foi observada uma tendência de aumento dos valores tanto para o andar quanto para o correr nas regiões do pé, exceto o mediopé.

\subsection{Correlação entre variáveis de pressão plantar e idade}

A pesquisa também teve como objetivo avaliar as possíveis correlações entre as variáveis de pressão plantar e o aumento da idade. Os resultados da Tabela 10 apresentam os valores de $r$ para as correlações entre as variáveis de pressão plantar e a idade em cada uma das regiões de análise do pé. As correlações significativas são destacadas com $\left(^{*}\right)$ para $p \leq 0,05$ ou $\left(^{* *}\right)$ para $p \leq 0,001$. 
Tabela 10. Correlação entre as variáveis da pressão plantar e a idade.

\begin{tabular}{ccccccc}
\hline & Total & Calcanhar & Mediopé & Antepé & Hálux & Dedos \\
\hline $\begin{array}{c}\text { Tempo de } \\
\text { Contato } \\
(\% \text { Total) }\end{array}$ & - & 0,081 & $-0,043$ & $0,302^{* *}$ & 0,070 & $0,342^{* *}$ \\
\hline $\begin{array}{c}\text { Pico de } \\
\text { Pressão (kPa) }\end{array}$ & 0,146 & $-0,049$ & $-0,086$ & $0,630^{* *}$ & $0,306^{* *}$ & $0,452^{* *}$ \\
\hline $\begin{array}{c}\text { Força Máxima } \\
(\mathbf{N})\end{array}$ & $0,802^{* *}$ & $0,826^{* *}$ & $-0,072$ & $0,772^{* *}$ & $0,623^{* * *}$ & $0,534^{* *}$ \\
\hline $\begin{array}{c}\text { Força Máxima } \\
(\% \text { PC) }\end{array}$ & $-0,418^{* *}$ & $-0,296^{* *}$ & $-0,483^{* *}$ & 0,162 & 0,015 & $-0,181$ \\
\hline $\begin{array}{c}\text { Área de } \\
\text { Contato }\left(\mathbf{c m}^{2}\right)\end{array}$ & $0,664^{* *}$ & $0,831^{* *}$ & $-0,089$ & $0,775^{* *}$ & $0,824^{* * *}$ & $0,568^{* *}$ \\
\hline $\begin{array}{c}\text { Área de } \\
\text { Contato } \\
(\% \text { Total) }\end{array}$ & - & $0,497^{* *}$ & $-0,491^{* *}$ & $0,381^{* *}$ & $0,393^{* * *}$ & 0,090 \\
\hline${ }^{* *} p \leq 0,001 ;{ }^{*} p \leq 0,05$ & & & & & \\
\hline
\end{tabular}

As correlações significativas indicam que a idade exerce influência com tamanho de efeito grande sobre o aumento nas variáveis plantares de valor absoluto, força máxima e área de contato, em todas as regiões de análise, com exceção do mediopé. As demais correlações significativas apresentam tamanhos de efeito considerados médios, dentre as quais podemos destacar a força máxima relativa, que apresenta correlação negativa com a idade, indicando uma relação inversamente proporcional.

\subsection{Correlação entre variáveis de pressão plantar e variáveis morfológicas}

O trabalho teve ainda o objetivo de verificar a existência de correlação entre as variáveis da pressão plantar e as variáveis morfológicas. A Tabela 11 apresenta os valores do coeficiente de correlação de Pearson $(r)$ entre as variáveis morfológicas e as variáveis plantares e indica as correlações significativas com $\left({ }^{*}\right)$ para $p \leq 0,05$ ou $\left({ }^{* *}\right)$ para $p \leq 0,001$. 
Tabela 11. Correlação entre variáveis de pressão plantar e variáveis morfológicas.

\begin{tabular}{|c|c|c|c|c|c|c|}
\hline & & Peso & Estatura & IMC & $\mathrm{CP}$ & IAP \\
\hline & PP & $0,379 * *$ & $0,378 * *$ & $0,216^{*}$ & 0,148 & $-0,382 * *$ \\
\hline \multirow{5}{*}{ Total } & Fmáx & $0,880 * *$ & $0,856^{* *}$ & $0,606^{* *}$ & $0,543 * *$ & $-0,341 * *$ \\
\hline & Fmáx\% & 0,065 & 0,172 & $-0,122$ & 0,047 & $-0,029$ \\
\hline & $\mathrm{AC}$ & $0,648 * *$ & $0,622 * *$ & $0,479 * *$ & $0,804 * *$ & 0,174 \\
\hline & TC\% & $-0,013$ & $-0,006$ & $-0,010$ & $0,205^{*}$ & 0,060 \\
\hline & $\mathbf{P P}$ & $-0,086$ & $-0,058$ & $-0,107$ & 0,178 & $-0,101$ \\
\hline \multirow{6}{*}{ Calcanhar } & Fmáx & $0,488 * *$ & $0,491 * *$ & $0,342 * *$ & $0,650 * *$ & $-0,211 *$ \\
\hline & Fmáx\% & $-0,350 * *$ & $-0,337 * *$ & $-0,235^{*}$ & 0,070 & 0,196 \\
\hline & $\mathbf{A C}$ & $0,639 * *$ & $0,634 * *$ & $0,454 * *$ & $0,868 * *$ & $-0,141$ \\
\hline & $\mathrm{AC} \%$ & 0,177 & $0,234^{*}$ & 0,075 & $0,468 * *$ & $-0,512 * *$ \\
\hline & TC\% & 0,043 & 0,012 & 0,076 & 0,043 & $0,461 * *$ \\
\hline & PP & $0,295 * *$ & $0,229^{*}$ & $0,306 * *$ & 0,112 & $0,200 *$ \\
\hline \multirow{6}{*}{ Mediopé } & Fmáx & 0,080 & 0,010 & 0,187 & 0,165 & $0,696 * *$ \\
\hline & Fmáx\% & $-0,397 * *$ & $-0,455^{* *}$ & $-0,178$ & $-0,177$ & $0,854 * *$ \\
\hline & $\mathrm{AC}$ & $-0,004$ & $-0,062$ & 0,100 & $0,235^{*}$ & $0,836 * *$ \\
\hline & $\mathrm{AC} \%$ & $-0,485^{* *}$ & $-0,553 * *$ & $-0,215^{*}$ & $-0,198 *$ & $0,949 * *$ \\
\hline & TC\% & 0,176 & $0,198 *$ & 0,060 &,$- 205^{*}$ & $-0,248^{*}$ \\
\hline & PP & $0,554 * *$ & $0,575^{* *}$ & $0,318 * *$ & $0,219^{*}$ & $-0,435 * *$ \\
\hline \multirow{6}{*}{ Antepé } & Fmáx & $0,846 * *$ & $0,845^{* *}$ & $0,537 * *$ & $0,437 * *$ & $-0,472 * *$ \\
\hline & Fmáx\% & $0,276^{* *}$ & $0,392 * *$ & 0,001 & 0,054 & $-0,376^{* *}$ \\
\hline & AC & $0,901 * *$ & $0,894 * *$ & $0,599 * *$ & $0,587 * *$ & $-0,451 * *$ \\
\hline & $\mathrm{AC} \%$ & $0,370 * *$ & $0,409 * *$ & 0,160 & $-0,248^{*}$ & $-0,690 * *$ \\
\hline & TC\% & $-0,045$ & $-0,035$ & $-0,029$ & $-0,239 *$ & $-0,048$ \\
\hline & PP & $0,425 * *$ & $0,436 * *$ & $0,238 *$ & 0,152 & $-0,436 * *$ \\
\hline \multirow{6}{*}{ Hálux } & Fmáx & $0,665^{* *}$ & $0,674 * *$ & $0,417 * *$ & $0,507 * *$ & $-0,393 * *$ \\
\hline & Fmáx\% & $-0,028$ & 0,041 & $-0,118$ & 0,097 & $-0,144$ \\
\hline & AC & $0,814 * *$ & $0,816^{* *}$ & $0,540 * *$ & $0,773 * *$ & $-0,331 * *$ \\
\hline & $\mathrm{AC} \%$ & $0,325 * *$ & $0,371 * *$ & 0,138 & $-0,044$ & $-0,762 * *$ \\
\hline & TC\% & 0,154 & 0,187 & 0,068 & $-0,095$ & $-0,275 * *$ \\
\hline & $\mathbf{P P}$ & $0,484 * *$ & $0,463^{* *}$ & $0,345^{* *}$ & $0,263 * *$ & $-0,234^{*}$ \\
\hline \multirow{4}{*}{ Dedos } & Fmáx & $0,628 * *$ & $0,583 * *$ & $0,495 * *$ & $0,445^{* *}$ & $-0,233 * *$ \\
\hline & Fmáx\% & $-0,259 * *$ & $-0,257 * *$ & $-0,163$ & $-0,116$ & 0,100 \\
\hline & $\mathrm{AC}$ & $0,666^{* *}$ & $0,665^{* *}$ & $0,451 * *$ & $0,546 * *$ & $-0,331 * *$ \\
\hline & $\mathrm{AC} \%$ & 0,138 & 0,138 & 0,092 & $-0,254 * *$ & $-0,543 * *$ \\
\hline
\end{tabular}

${ }^{\star *} p \leq 0,001 ;{ }^{*} p \leq 0,05$ 
O peso corporal e a estatura apresentam comportamento similar, exercendo maior efeito sobre as variáveis da pressão plantar nas regiões do antepé, hálux e dedos. $\mathrm{Na}$ área total do pé e no calcanhar, efeitos considerados grandes foram vistos apenas para a força máxima e a área de contato absolutas, enquanto, no mediopé, foram encontradas correlações negativas com a força máxima e a área de contato relativas. O IMC e o comprimento do pé apresentaram maior influência sobre a Fmáx e AC, com grande tamanho de efeito na área total e nas regiões do antepé, hálux e dedos.

As correlações significativas com o índice do arco plantar apresentaram maior tamanho de efeito na região do mediopé para as variáveis TC\%, Fmáx, Fmáx\%, AC e AC\%. O IAP exerceu grande influência sobre a área de contato relativa em todas as regiões, exceto a área total do pé. 


\section{DISCUSSÃO}

O objetivo do trabalho foi descrever o comportamento de variáveis antropométricas e da distribuição da pressão plantar na faixa etária de 4 a 10 anos, durante $o$ andar e o correr, verificando as possíveis diferenças entre esses movimentos.

Os principais resultados demonstram que, em geral, as variáveis plantares apresentaram valores mais altos durante o correr em relação ao andar. Entretanto, foram observados aumentos das variáveis para o andar na região do calcanhar. Os dados apresentaram tendências a aumentos com a idade na maior parte das regiões de análise, enquanto na região do mediopé a tendência foi de que os valores fossem reduzidos.

As diferenças significativas entre as cargas plantares durante $o$ andar e 0 correr, bem como as tendências apresentadas com o aumento da idade ocorreram tanto para as variáveis absolutas quanto para os valores normalizados.

Foi encontrada relação entre a idade e as variáveis morfológicas com a distribuição da pressão plantar, principalmente para as variáveis absolutas força máxima e área de contato. A força máxima relativa apresentou correlações negativas com a idade, o peso e a estatura, indicando relações inversamente proporcionais. Já as correlações significativas com o índice do arco plantar foram encontradas principalmente para a área de contato relativa em todas as regiões do pé e para as demais variáveis na região do mediopé.

\subsection{Tempo de Contato}

$\mathrm{Na}$ análise dos resultados referentes ao tempo de contato relativo, foram apresentados valores significativamente mais altos para o andar nas regiões do calcanhar e do mediopé. Esse resultado pode estar associado a um padrão de rolamento com o pé todo executado durante a marcha, além da menor velocidade de movimento, mantendo o calcanhar e a região medial em contato com o solo por mais tempo. O padrão de movimento durante o correr, também pode influenciar o TC\% com o solo já que um ataque com o 
antepé pode reduzir o tempo de contato do calcanhar e do mediopé (41). Resultados semelhantes foram relatados em estudo que comparou o trote $\mathrm{e}$ a corrida em adolescentes, encontrando um maior tempo de contato absoluto na área total do pé durante o trote (17).

O tempo de contato relativo do hálux e dos dedos durante o correr foi significativamente maior em relação ao andar para todos os grupos. Aumentos do TC\% na região do hálux foram relatados anteriormente na avaliação do primeiro ano de marcha independente (3). Com a eventual redução do contato da porção posterior do pé durante o correr, a área dos dedos permanece no solo durante a maior parte do tempo de contato total com o solo, aumentando seus valores relativos.

No mediopé, a tendência de menor tempo de contato foi relatada em estudos anteriores que associaram esse comportamento ao crescimento e ao ganho de estabilidade no movimento (3).

\subsection{Pico de Pressão}

Resultados do pico de pressão indicaram cargas maiores durante o correr em comparação ao andar, exceto na região do calcanhar. Valores mais altos de PP em toda a área do pé para o correr em relação ao andar em adultos (41) e em relação ao aumento da velocidade em análises da marcha e da corrida $(14,17,18)$ foram relatados em vários estudos.

Todas as regiões do pé apresentaram tendência a maiores picos de pressão com o aumento da idade. Conforme descrito previamente, os aumentos da carga plantar com o crescimento são esperados, devido aos ganhos na estatura e no peso corporal das crianças (2-5). Apenas o mediopé apresentou decréscimo de seus valores em relação ao aumento da idade, o que pode estar associado ao desenvolvimento do arco longitudinal plantar (4).

As regiões do calcanhar e hálux obtiveram os maiores valores de PP durante $\mathrm{o}$ andar e o correr, respectivamente. Resultados de análise da marcha em crianças apresentaram valores mais altos no calcanhar $(3,4)$ e 
também no hálux $(5,37)$. A observação de picos de pressão sob o hálux durante a marcha parece ser uma característica de padrões imaturos ou em desenvolvimento $(2,36)$. Para o correr em adultos, os maiores picos de pressão parecem estar posicionados sob o hálux e na porção medial do antepé, sendo associados a uma maior inversão do complexo pé-tornozelo causado pelo aumento da velocidade $(18,41)$.

\subsection{Força Máxima}

A força máxima absoluta foi maior para o correr em todas as regiões do pé analisadas, com exceção do calcanhar. Os aumentos nos valores da Fmáx são consistentes com a literatura, que encontrou, em estudos com adultos, valores mais altos para o correr em relação ao andar, bem como para o aumento da velocidade durante o andar e o correr $(14,17,18,41)$.

Tendências de aumento da Fmáx com a idade também foram apresentados para todas as regiões com exceção do mediopé. Segundo estudos anteriores, aumentos nas cargas plantares são esperados devido ao ganho de peso e estatura durante o crescimento $(3,4)$. Da mesma forma que para o pico de pressão, o mediopé apresentou um comportamento contrário às demais regiões, com tendência a valores menores com 0 aumento da idade durante o andar. Segundo Hennig (48), maiores cargas sob a região do mediopé em crianças mais novas podem indicar que o arco plantar ainda é uma estrutura pouco resistente às sobrecargas.

Os maiores valores de Fmáx foram identificados nas regiões do calcanhar para o andar e do antepé durante o correr. Cargas maiores geralmente são identificadas na região do calcanhar para ambos os movimentos $(3,18,41)$, no entanto, o aumento da velocidade do movimento tende a influenciar o deslocamento do contato inicial do calcanhar para o antepé (38). 


\subsection{Força Máxima Normalizada}

Ao analisar os dados da força máxima relativa, podemos observar a mesma tendência encontrada para os dados absolutos, com maiores valores de força durante o correr em comparação ao andar. Esse resultado está de acordo com a literatura que comparou o andar e o correr em adultos (41) e pode ser importante para destacar que as diferenças entre as sobrecargas exercidas durante a marcha e a corrida continuam sendo significativas mesmo com a normalização dos dados pelo peso corporal.

Com o aumento da idade, é possível notar tendências de diminuição da variável na área total do pé durante o andar, e nas regiões do calcanhar, mediopé e dedos em ambos os movimentos. A redução dos valores de Fmáx\% foi relatada previamente durante a marcha de crianças apenas para a região do mediopé (2) e para as demais regiões na comparação com adultos (37). Um estudo sobre a simetria da marcha de crianças em comparação com adultos indicou que o índice de assimetria em relação à Fmáx\% é reduzido com o aumento da idade (6). Dessa forma, é possível que os resultados encontrados indiquem que o padrão do movimento está sendo amadurecido, fazendo necessário o uso de menos força para executar um movimento já estabilizado.

\section{5. Área de Contato}

Na comparação entre o andar e o correr, a área de contato absoluta é maior para o correr em todas as regiões, exceto o calcanhar. Esses resultados estão de acordo com estudos que relacionam o aumento da $\mathrm{AC}$ durante o correr a fatores biomecânicos $(17,18,41)$. A área de contato do calcanhar apresentou poucas diferenças significativas entre 0 andar e 0 correr, o que pode estar relacionado ao fato de que foram selecionadas para análise nesse estudo apenas as tentativas que possuíam contato inicial do calcanhar.

A área de contato está relacionada ao tamanho do pé das crianças e, por isso, espera-se que, com o aumento da idade, seus valores também sejam 
maiores (5). Diversos estudos relatam aumentos significativos da AC em função do crescimento da criança $(3,4)$. Os resultados deste trabalho corroboram com os estudos citados, apresentando valores crescentes da AC em todas as regiões do pé, com exceção do mediopé. Segundo Bosch (2), a redução da $A C$ na região do mediopé está fortemente associada ao desenvolvimento do arco plantar.

\section{6. Área de Contato Relativa}

Da mesma forma que para os valores absolutos, verificou-se na região do calcanhar uma maior área de contato relativa durante o andar. Por outro lado, para o correr a área de contato se mostrou significativamente maior na região do mediopé. A atuação de forças de maior magnitude durante o correr pode acarretar uma depressão do arco plantar e consequente aumento da área de contato na região do mediopé (49).

Observando o comportamento da variável com a idade, é possível notar uma tendência de diminuição da área de contato no mediopé, possivelmente associada ao desenvolvimento do arco longitudinal plantar, e aumento dos valores nas demais regiões associado ao crescimento das crianças $(2,5)$.

\subsection{Relação entre distribuição da pressão plantar, idade e variáveis morfológicas}

A partir dos dados antropométricos podemos compreender e caracterizar o processo de crescimento de crianças. As influências da idade e das variáveis morfológicas sobre a pressão plantar na infância já foram relatadas previamente $(2-4,50)$.

De acordo com os resultados deste estudo, as principais correlações com a idade e as variáveis morfológicas foram vistas com a força máxima e área de contato absolutas. O aumento nas variáveis pode ser relacionado aos aumentos contínuos de peso corporal, estatura, IMC e comprimento do pé, uma vez que 
esses valores não foram normalizados e mostram a relação direta entre as alterações na DPP e o processo de maturação (3).

Por outro lado, força máxima e área de contato relativas apresentaram correlações negativas com a idade e as variáveis peso e estatura. Esse resultado expressa uma relação inversamente proporcional que indica diminuição das variáveis plantares com os aumentos de idade, peso e estatura. Apesar de os resultados deste estudo estarem de acordo com a literatura, apresentando tendências de aumento dessas variáveis com a idade (3), essa relação inversa possivelmente pode ser explicada pelo ganho de estabilidade na marcha e na corrida, resultando em movimentos com maior controle do indivíduo e, consequentemente, menores cargas plantares.

A análise da correlação entre o comprimento do pé e a DPP, permite identificar considerável tamanho de efeito do aumento do comprimento sobre a pressão plantar na maior parte das regiões, excetuando o mediopé. No aumento do $\mathrm{CP}$ encontrado em estudos anteriores, verificou-se que esse processo é mais acelerado até os 3 anos de idade e se mantém constante nos próximos anos até por volta dos 12 anos de idade $(2-4,31)$.

A correlação do índice do arco plantar com a distribuição da pressão plantar indicou influência significativa sobre todas as variáveis plantares na região do mediopé, resultado que sugere o desenvolvimento do arco longitudinal plantar com o aumento da idade (30). Os dados deste estudo corroboram com a literatura, apresentando redução do IAP com o aumento da idade (2-4). Um estudo que avaliou a impressão plantar estática de crianças de 0 a 15 anos de idade relatou que o índice de contato da região medial do pé com o solo sofreu um decréscimo acelerado até os 6 anos de idade, e que passou a ser mais lento até os 10 anos, após isso, esse valor foi mantido. Esse comportamento sugere que o arco longitudinal plantar se desenvolve mais rapidamente no início da infância e encerra o seu desenvolvimento por volta dos 10 anos (31). 


\section{CONCLUSÕES}

Os resultados apresentados neste trabalho indicam que os valores das variáveis de pressão plantar são mais altos para o correr em relação ao andar em crianças de 4 a 10 anos. As diferenças entre os movimentos puderam ser observadas tanto em variáveis absolutas como naquelas com dados relativos e normalizados. As maiores cargas plantares podem estar associadas aos aumentos no peso corporal e na estatura dos participantes. Foram encontradas tendências de valores crescentes das variáveis plantares na área total do pé e nas regiões do calcanhar, antepé, hálux e dedos e de diminuição dos valores no mediopé, que estão possivelmente associadas ao processo de maturação das crianças.

A idade e as variáveis morfológicas apresentaram correlações significativas com as variáveis de pressão plantar, indicando que existe influência desses fatores sobre a distribuição da pressão plantar, principalmente para variáveis nãonormalizadas. $O$ aumento da idade está associado aos processos que representam a maturação das crianças, tais quais os maiores valores de peso, estatura, índice de massa corpórea e comprimento do pé, e à redução do índice do arco plantar. Dessa forma, os resultados apresentados para as variáveis plantar na comparação entre o andar e o correr são corroborados pelas relações encontradas entre a distribuição de pressão plantar, a idade e as variáveis morfológicas.

A análise da distribuição da pressão plantar pode facilitar o entendimento a respeito do funcionamento do pé em atividades dinâmicas, podendo contribuir para a aplicações clínicas, programas de atividade física ou desenvolvimento de calçados. Os resultados apresentados neste trabalho podem ser utilizados como referência para comparação com estudos que avaliem o andar e o correr de crianças e adultos. 


\section{REFERÊNCIAS BIBLIOGRÁFICAS}

1. Barr EA, Backus SI. Biomecânica da Marcha. In: Margareta Nordin VHF, editor. Biomecânica Básica do Sistema Musculoesquelético: Guanabara Koogan; 2003.

2. Bosch K, Gerss J, Rosenbaum D. Development of healthy children's feet - Nine-year results of a longitudinal investigation of plantar loading patterns. Gait \& posture. 2010;32:564-71.

3. Bertsch C, Unger H, Winkelmann W, Rosenbaum D. Evaluation of early walking patterns from plantar pressure distribution measurements. First year results of 42 children. Gait \& posture. 2004;19(3):235-42. Epub 2004/05/06.

4. Müller S, Carlsohn A, Baur H, Mayer F. Static and dinamic foot characteristics in children aged 1-13 years: A cross sectional study. Gait \& posture. 2012;35:389-94.

5. Bosch K, Gerss J, Rosenbaum D. Preliminary normative values for foot loading parameters of the developing child. Gait \& posture. 2007;26:238-47.

6. Bosch K, Rosenbaum D. Gait symmetry improves in childhood - A 4-year follow-up of foot loading data. Gait \& posture. 2010;32:464-8.

7. Phetean J, Nester CJ. The influence of body weight, body mass index and gender on plantar pressures: Results of a cross-sectional study of healthy children's feet. Gait \& posture. 2012;36:287-90

8. Mickle KJ, Steele JR, Munro BJ. Is the foot structure of preschool children moderated by gender? J Pediatr Orthop. 2008;28(5):593-6.

9. Mickle KJ, Steele JR, Munro BJ. Does excess mass affect plantar pressure in young children? International Journal of Pediatric Obesity. 2006;1(3):183-8.

10. da Rocha ES, Bratz DTK, Guber LC, De David AC, Carpes FP. Obese children experience higher plantar pressure and lower foot sensitivity than non-obese. Clin Biomech. 2014.

11. Mariano CRE, de David AC. Variáveis espaço-temporais do andar em velocidade lenta, livree rápida em crianças de 3 a 8 anos. R da Educação Física/UEM. 2010;21(4):625-32.

12. Schwartz MH, Rozumalski A, Trost JP. The effect of walking speed on the gait of typically developing children. Journal of Biomechanics. 2008;41:1639-50.

13. Lythgo N, Wilson C, Galea M. Basic gait symmetry measures for primary school-aged children and young adults. II: Walking at slow, free and fast speed. Gait \& posture. 2011;33:29-35.

14. Rosenbaum D, Hautmann S, Gold M, Claes L. Effects of walking speed on plantar pressure patterns and hindfoot angular motion. Gait \& posture. 1994;2:191-7.

15. Cavanagh PR, Lafortune MA. Ground reaction forces in distance running. J Biomechanics. 1980;13:397-406.

16. Munro CF, Miller DI, Fuglevand AJ. Ground reaction forces in running: a reexamination. J Biomechanics. 1987;20(2):147-55.

17. Fourchet F, Kelly L, Horobeanu C, Loepelt H, Taiar R, Millet GP. Comparison of plantar pressure distribution in adolescent runners at low vs. high running velocity. Gait \& posture. 2012;35:685-7.

18. Ho I-J, Hou Y-Y, Yang C-H, Wu W-L, Chen S-K, Guo L-Y. Comparison of plantar pressure distribution between different speed and incline during treadmill jogging. Journal of Sports Science and Medicine. 2010;9:154-60.

19. Magil R. Aprendizagem Motora: Conceitos e Aplicações. São Paulo: Blucher; 2000.

20. Teixeira LA. Controle Motor. Edição a, editor. Barueri, SP: Editora Manole; 2006.

21. Lent R. Cem bilhões de neurönios: Conceitos fundamentais de neurociëncias. São Paulo: Atheneu; 2004.

22. Perry J, Burnfield JM. Gait Analysis: Normal and Pathological Function. Second ed: Slack Incorporated; 2010. 551 p. 
23. Purves D, Augustine G, Fitzpatrick D, Hall W, LaMantia A-S, McNamara J, et al. Neurociëncias. 4 ed. Porto Alegre: Artmed; 2010.

24. Gallahue DL, Ozmun JC. Compreendendo o Desenvolvimento Motor: Bebês, crianças, adolescentes e adultos. 3, editor. São Paulo: Phorte; 2001.

25. Brenière $Y$, Bril B. Development of postural control of gravity forces in children during the first 5 years of walking. Exp Brain Res. 1998;121:255-62.

26. Bril $B$, Brenière $Y$. Postural requirements and progression velocity in young walkers. Journal of Motor Behavior. 1992;24(1):105-16.

27. Sutherland D. The development of mature gait. Gait \& posture. 1997;6:163-70.

28. Sammarco GJ, Hockenbury RT. Biomecânica do Pé e do Tornozelo. In: Margareta Nordin VHF, editor. Biomecânica Básica do Sistema Musculoesquelético: Guanabara Koogan; 2003.

29. Putti AB, Arnold GP, Cochrane LA, Abboud RJ. Normal pressure values and repeatability of the Emed $^{\circledR}$ ST4 system. Gait \& posture. 2008;27:501-5.

30. McCrory JL, Young MJ, Boulton AJM, Cavanagh PR. Arch index as a predictor of arch height. The Foot. 1997; 7:79-81.

31. Volpon JB. Footprint analysis during the growth period. J Pediatr Orthop. 1994;14:83 - 5 .

32. Syed N, Karvannan H, Maiya AG, Binukumar B, Prem V, Chakravarty RD. Plantar pressure among assymptomatic individuals: A cross-sectional study. Foot Ankle Spec. 2012;5:102-6.

33. Anderson M, Blais M, Green W. Growth of the normal foot during childhood and adolescence: length of foot and interrelations of foot, stature, and lower extremity as seen in serial records of children between 1 - 18 years of age. Am J Phys Antropol. 1956;14:287 - 308.

34. Cheng J, Leung S, Leung A. Change of foot size with weightbearing. A study of 2829 children 3 to 18 years of age. Clin Orthop. 1997;342(123).

35. Orlin MN, McPoil TG. Plantar Pressure Assessment. Physical therapy. 2000;80:399-409.

36. Hallemans A, D'Août K, Clerqc DD, Aerts P. Pressure distribution patterns under the feet of new walkers: The first two months of independent walking. Foot $\&$ ankle international.

2003;24(5):444-53.

37. Bosch K, Nagel A, Weigend L, Rosenbaum D. From "first" to "last" steps in life - Pressure patterns of three generations. Clin Biomech. 2009;24:676-81.

38. Novacheck TF. The Biomechanics of Running. Gait \& posture. 1998;7:77-95.

39. Õunpuu $\mathrm{S}$. The biomechanics of walking and running. Clinics in Sports Medicine. 1994;13(4):843-63.

40. Pauk J, Daunoraviciene K, Ihnatouski M, Griskevicius J, Raso JV. Analysis of the plantar pressure distribution in children with foot deformities. Acta of bioengineering and biomechanics / Wroclaw University of Technology. 2010;12(1):29-34. Epub 2010/07/27.

41. Chuckpaiwong B, Nunley JA, Mall NA, Queen RM. The effect of foot type on in-shoe plantar pressure during walking and running. Gait \& posture. 2008;28:405-11.

42. Sampieri R, Collado C, Lucio M. Metodologia de Pesquisa. 5, editor. Porto Alegre: Penso; 2013.

43. Cole TJ, Bellizzi MC, Flegal KM, Dietz WH. Establishing a standard definition for child overweight and obesity worldwide: international survey. BMJ. 2000;320:6.

44. Goble DJ, Marino GW, Potvin JR. The influence of horizontal velocity on interlimb symmetryin normal walking. Hum Mov Sci. 2003;22:271 - 83.

45. McPoil TG, Cornwall MW, Dupuis L, Cornwell M. Variability of plantar pressure data. A comparison of the two-step and midgait methods. Journal of the American Podiatric Medical Association. 1999;89:547 - 51.

46. Cavanagh PR, Rodgers MM. The arch index: a useful measure from footprints. J Biomechanic. 1987;20(5):547-51.

47. Field A. Descobrindo a estatística usando o SPSS. 2 ed. Porto Alegre: Artmed; 2009. 
48. Hennig EM, Staats A, Rosenbaum D. Plantar pressure distribution patterns of young school children in comparison to adults. Foot \& ankle international. 1994;15(1):35-40. Epub 1994/01/01. 49. Vieira TN. Distribuição de pressão plantar durante o correr em crianças. Brasília: Universidade de Brasília; 2014.

50. Scott G, Mez HB, Newcombe L. Age-related differences in foot structure and function. Gait \& posture. 2007;26:68-75. 
ANEXO I - Parecer de aprovação do comitê de ética

\author{
$\varnothing$ \\ Universidade de Brasília \\ Faculdade de Ciências da Saúde \\ Comitê de Ética em Pesquisa - CEP/FS
}

PROCESSO DE ANÁLISE DE PROJETO DE PESQUISA

Título do Projeto: "DISTRIBUIÇÃO DA PRESSÃO PLANTAR DURANTE O ANDAR E CORRER EM CRIANÇAS".

Pesquisadora Responsável: Paula Ribeiro Mesquita

Data de Entrada: 23/02/2015

CAAE: 35735314.1 .0000 .0030

Com base na Resolução 466/12, do CNS/MS, que regulamenta a ética em pesquisa com seres humanos, o Comitê de Ética em Pesquisa com Seres Humanos da Faculdade de Ciências da Saúde da Universidade de Brasília, após análise dos aspectos éticos e do contexto técnico-científico, resolveu APROVAR o projeto intitulado "DISTRIBUIÇÃO DA PRESSÃO PLANTAR DURANTE O ANDAR E CORRER EM CRIANÇAS". Parecer n 988.313, em 18 de março de 2015.

Notifica-se o(a) pesquisador(a) responsável da obrigatoriedade da apresentação de um relatório semestral e relatório final sobre o desenvolvimento do projeto, no prazo de 1 (um) ano a contar da data de aprovação.

Brasília, 29 de abril de 2015.

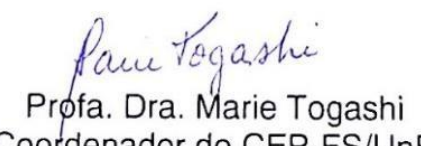

Coordenador do CEP-FS/UnB

gun. (SH/d JJ) soveunh sales wos

esjnbsad we no!n ep eq

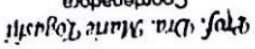


Anexo II - Relatório de processamento dos dados gerado pelo sistema Emed/R

\section{novelde}

\section{sicence}

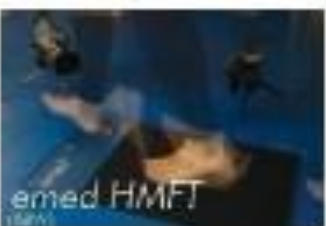

Patient

Patiort First name. Last name:

Date of birth

Gonder: fomals

Comments

Diagnosis, resulter

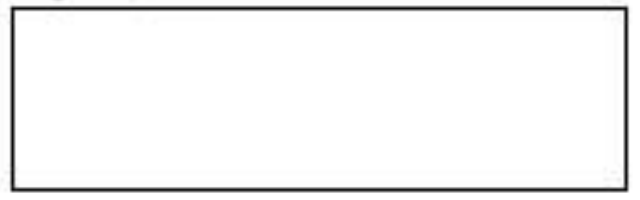

Conclusion, therapy

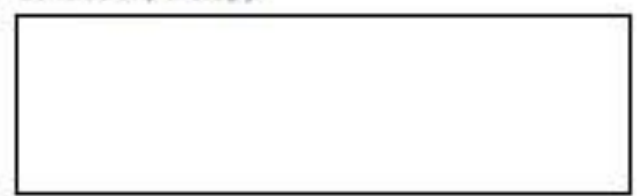

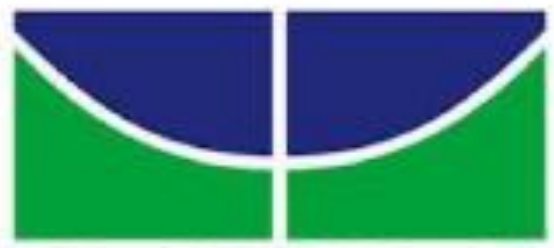

\section{Toffuersidado de Brasilla}

pedography resulte
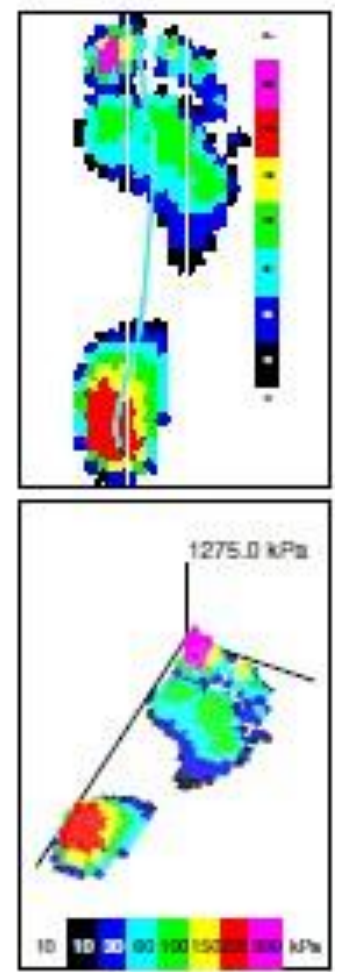

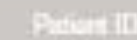

(ativent

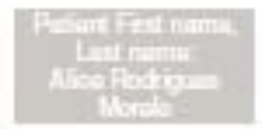

$-1$. 

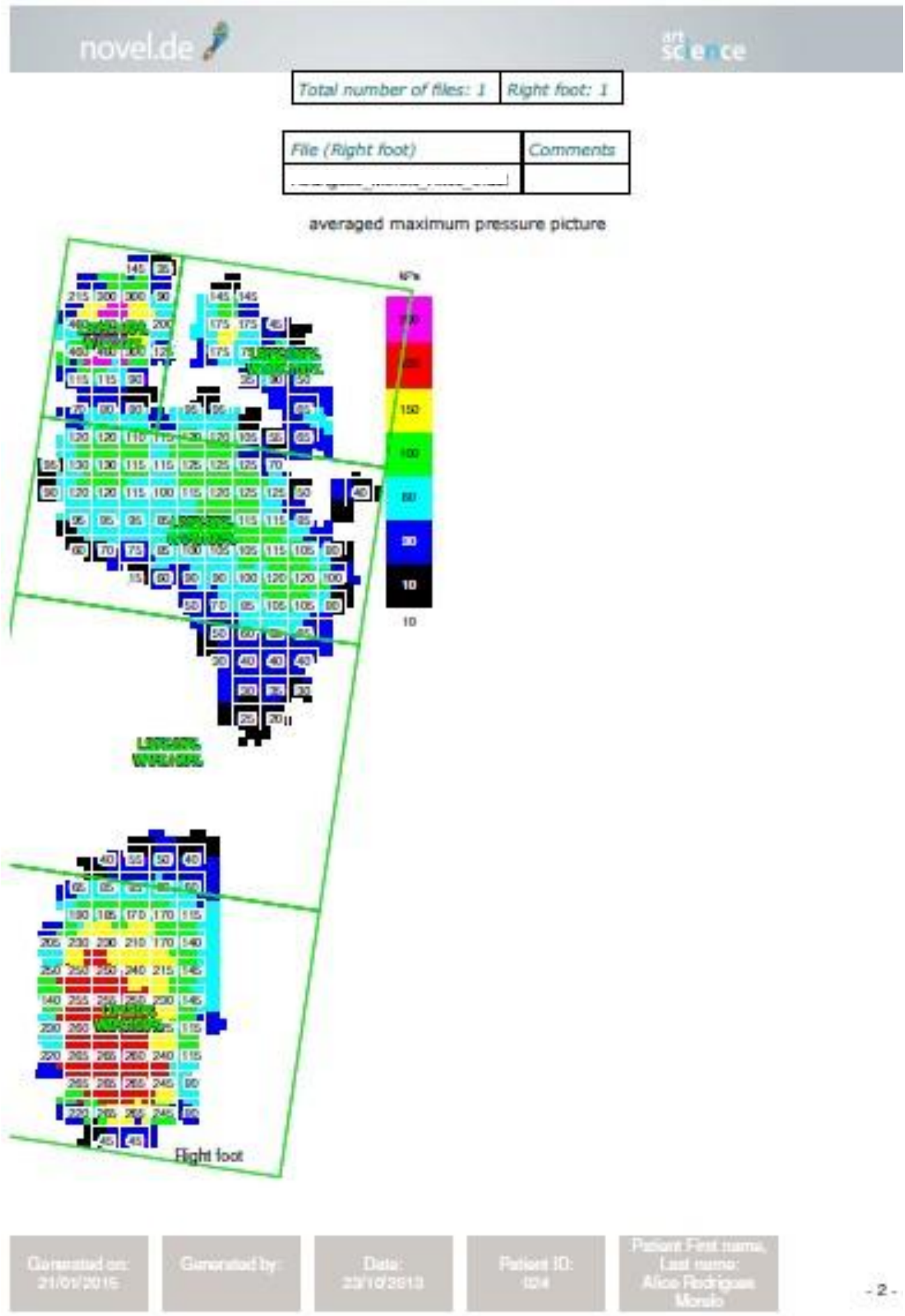

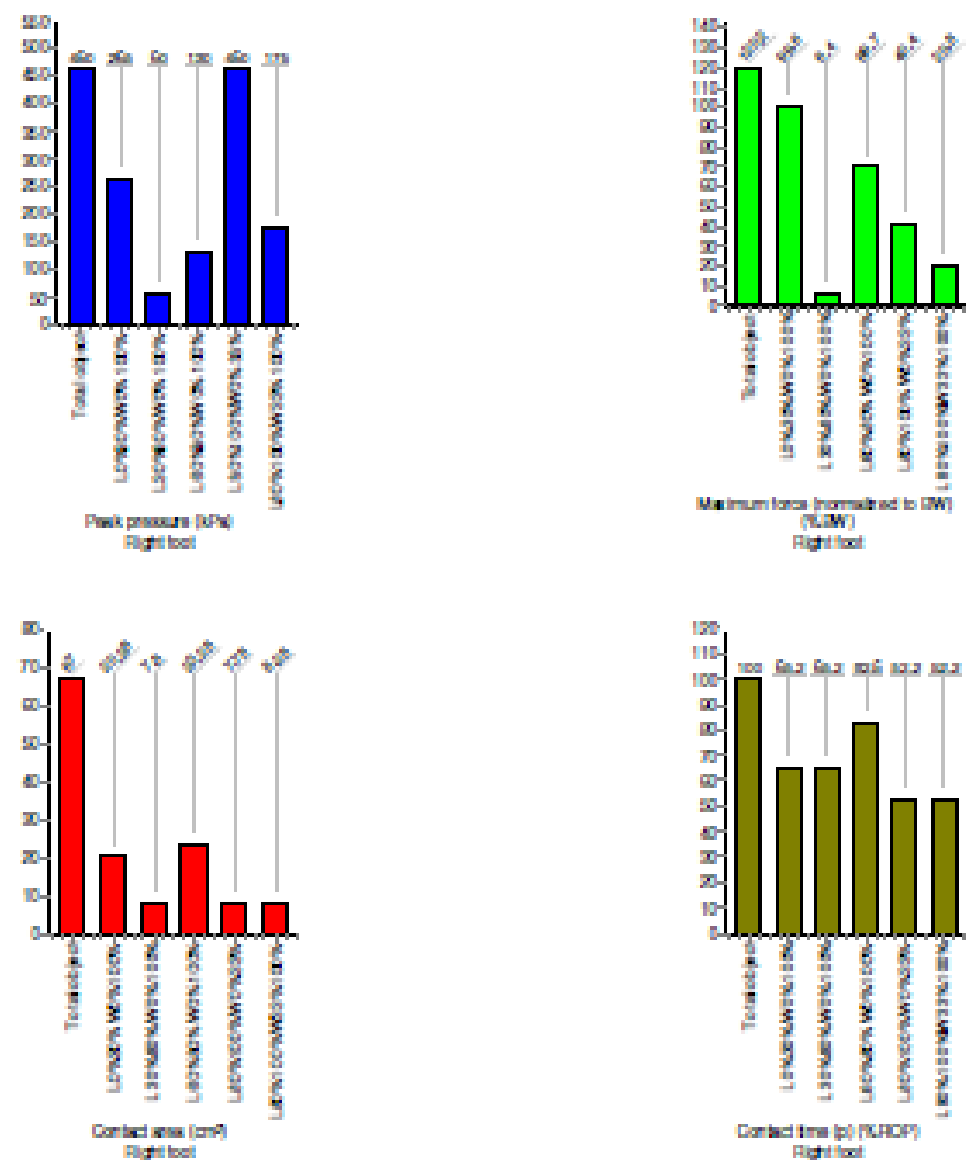


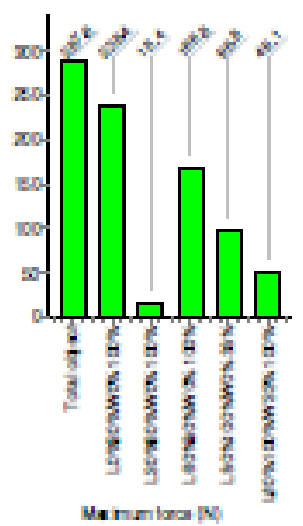

$$
\begin{gathered}
\text { emanlana RY } \\
\text { Angt bel }
\end{gathered}
$$

Parameters ) masks (statistics)

\begin{tabular}{|c|c|c|c|c|c|c|}
\hline Parameters & $\begin{array}{l}\text { Total } \\
\text { object }\end{array}$ & $20 \% 30$ & 1309 & L60\%s: & L80\% & L.80\% \\
\hline \multicolumn{7}{|c|}{ Right foot } \\
\hline Maximum forco $(\mathbb{N})$ & $28 \pi, 6$ & 238,4 & 15,4 & 165,8 & 96,8 & 49,1 \\
\hline Maximum forco (normalizod to BW) (s:BW) & 120,2 & 99,6 & 6,4 & 62,7 & 40,4 & 20,5 \\
\hline Plodk prossuro $(\mathrm{kPa})$ & 460,0 & 265,0 & 60,0 & 130,0 & 460,0 & 175,0 \\
\hline Contact time (p) ( $(\mathrm{AHOP})$ & 100,0 & 65,2 & 65,2 & 82,6 & 52,2 & 52,2 \\
\hline Contact area $\left(\mathrm{cm}^{2}\right)$ & 67,00 & 20,25 & 7,50 & 23,25 & 7,75 & 8,25 \\
\hline
\end{tabular}


aversoed maximum pressure picture

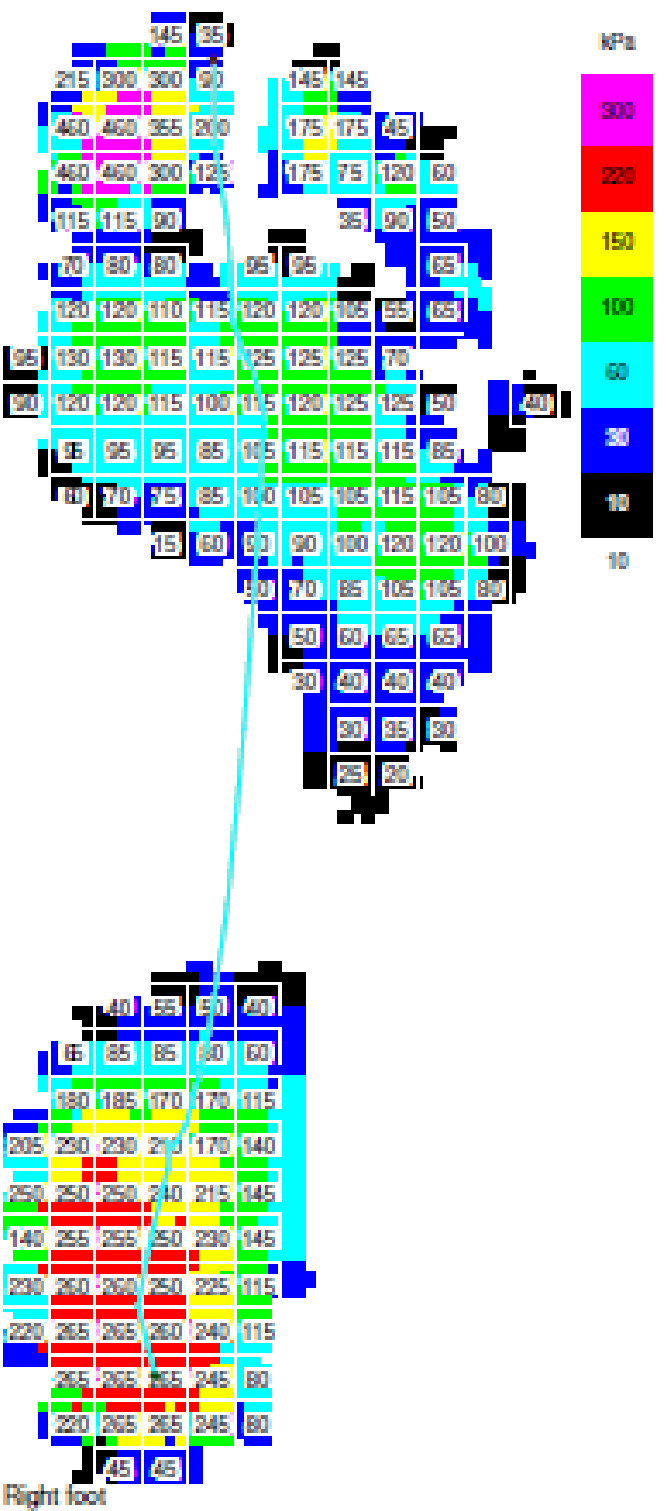


Apêndice I - Ficha cadastral e questionário

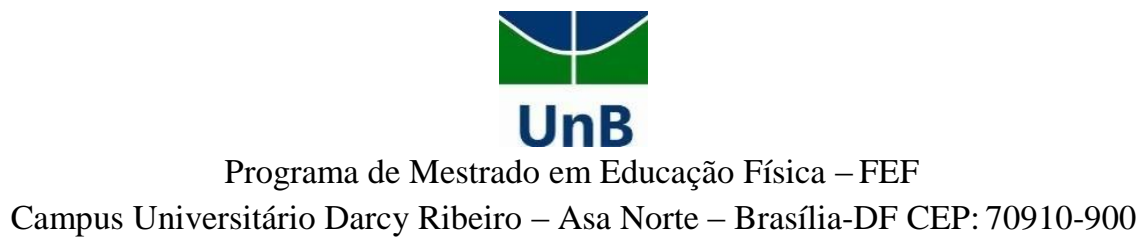

FICHA CADASTRAL

\section{DADOS DO ALUNO}

NOME:

DATA DE NASCIMENTO:

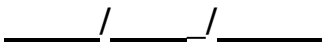

ALTURA: cm.

\section{PESO:} kg.

\section{As medidas serão preenchidas pelos pesquisadores}

\section{HISTÓRICO}

Prezado Pai/ Responsável,

1. Seu filho possui algum problema musculoesquelético ou mecânico que prejudique a marcha (caminhada) e/ou a corrida?
$\square$ SIM
$\square \mathrm{NÃO}$

QUAL?

2. Seu filho realiza atividade física/ esportes de forma contínua?
$\square$ SIM
$\square \mathrm{NÃO}$

QUAL?

QUANTAS VEZES NA SEMANA?

Obrigada pela participação! 


\title{
Apêndice II - Carta convite para participação em pesquisa
}

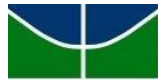 \\ UnB \\ Faculdade de Educação Física \\ Campus Universitário Darcy Ribeiro - Asa Norte - Brasília-DF CEP: 70910-900
}

A Faculdade de Educação Física da Universidade de Brasília está realizando uma pesquisa com o objetivo de avaliar o desenvolvimento da marcha em crianças saudáveis.

A pesquisa intitulada: "DESENVOLVIMENTO DO ANDAR E DO CORRER EM CRIANÇAS" aprovada no Comitê de Ética da Faculdade de Medicina da UnB sob o nº 006/2009, está sendo desenvolvida pela professora de Educação Física Paula Ribeiro Mesquita sob orientação da Profa. Dra. Ana Cristina de David - Laboratório de Análise do Movimento Humano da FEF - UnB.

As crianças participantes do presente estudo não serão colocadas em nenhuma situação de desconforto ou constrangimento, uma vez que as coletas não apresentam riscos. Os resultados obtidos nas coletas serão apenas utilizados para análise e tratamento dos dados pelos próprios pesquisadores, com finalidade científica. Os dados ficarão sob responsabilidade dos autores da pesquisa e armazenados no Laboratório de Análise do Movimento Humano da UnB por um período de 2 anos, sendo, após este período, destruídos.

As medidas serão realizadas no ambiente da escola, em momentos oportunos definidos pela direção da escola e pela professora responsável da sala de aula. Serão realizadas medidas de estatura e peso corporal dos alunos de 4 a 10 anos de idade. Serão selecionadas crianças para realizar o teste de caminhada e corrida por meio de uma plataforma de distribuição da pressão plantar. Cada sessão deve durar em torno de 20 minutos para cada aluno.

Salienta-se que, ao final do estudo, os resultados obtidos serão disponibilizados para a direção da escola, fornecendo informações importantes para um planejamento e também para avaliação do programa de atividade física já existente. Será garantido o anonimato dos alunos na divulgação dos resultados do estudo. Será, ainda, fornecido um Termo de Consentimento Livre e Esclarecido que deverá ser assinado pelos responsáveis dos alunos como critério de inclusão na pesquisa.

A pesquisa não trará prejuízo alguns aos indivíduos participantes e eles encontram-se livres para abandonar a pesquisa quando julgarem necessário.

Agradecemos a compreensão.

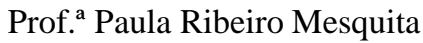

Prof. ${ }^{\text {a }}$ Dr ${ }^{\mathrm{a}}$. Ana Cristina de David

E-mail: paulamesquitaa@hotmail.com / Tel.: (61)9163-6999 


\title{
Apêndice III - Declaração de ciência institucional
}

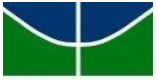 \\ UnB \\ Programa de Mestrado em Educação Física - FEF \\ Campus Universitário Darcy Ribeiro - Asa Norte - Brasília-DF CEP: 70910-900
}

\begin{abstract}
PESQUISA: "DESENVOLVIMENTO DO ANDAR E DO CORRER EM CRIANÇAS"
PESQUISADORA RESPONSÁVEL: PAULA RIBEIRO MESQUITA

TELEFONES PARA CONTATO: (61) 9163-6999/ (61) 3036-9753

ORIENTADORA: ANA CRISTINA DE DAVID
\end{abstract}

\section{Declaracão de Ciência Institucional}

$\mathrm{Eu}$, de livre e espontânea vontade, autorizo a participação dos alunos na pesquisa: "DESENVOLVIMENTO DO ANDAR E DO CORRER EM CRIANÇAS", sob minha responsabilidade.

Estou informado de que, quando julgar necessário, e sem qualquer prejuízo, poderei cancelar este termo. Consinto que os alunos sob minha responsabilidade realizem medidas antropométricas (estatura e peso corporal) e o teste de caminhada e corrida na plataforma de distribuição da pressão plantar da marca Emed.

Fui informado de que a aplicação dos procedimentos não acarretará prejuízo ou dano algum aos alunos e que, em caso de dúvidas, posso entrar em contato com a pesquisadora responsável para saná-las.

Certifico que tive a oportunidade de ler e entender os termos e as palavras contidas no termo acima e me foram dadas explicações referentes a ele.

Brasília, abril de 2014

Nome da Instituição:

Nome do (a) Coordenador (a):

Assinatura Coordenador (a)

Assinatura da Pesquisadora Responsável 


\title{
Apêndice IV - Termo de consentimento livre e esclarecido
}

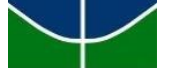 \\ UnB \\ Programa de Mestrado em Educação Física - FEF \\ Campus Universitário Darcy Ribeiro - Asa Norte - Brasília-DF CEP: 70910-900
}

\section{TERMO DE CONSENTIMENTO LIVRE ESCLARECIDO PARA PARTICIPACÃO EM PESOUISA}

Prezado (s) alunos, pai (s) ou responsável (s),

A Faculdade de Educação Física da Universidade de Brasília (UnB) está realizando uma pesquisa para avaliar o desenvolvimento do andar e o do correr em crianças de 4 a 10 anos de idade. A pesquisa consiste na medição da estatura e peso corporal, além de um teste para medir a distribuição da pressão na planta do pé por meio de uma plataforma eletrônica.

Dessa forma, venho, por meio deste, convidar seu filho a participar dessa pesquisa. A participação é voluntária e gratuita e os testes realizados não apresentam nenhum tipo de risco à saúde. Poderá haver a qualquer momento desistência da participação sem nenhum prejuízo e as informações fornecidas têm garantia de sigilo por parte dos pesquisadores. Vale destacar que estaremos à disposição para esclarecer quaisquer dúvidas que possam surgir ao longo do período de testes.

Esta pesquisa é coordenada pela Profa. Dra. Ana Cristina de David e pela professora Paula Ribeiro Mesquita, que se colocam à disposição para esclarecimentos adicionais.

Coordenação Local: Paula Ribeiro Mesquita

E-mail: paulamesquitaa@hotmail.com

Tel.: (61) 9163-6999 / (61) 3036-9753

Coordenação Geral: Ana Cristina de David

E-mail: acdavid@unb.br

Tel.: (61) 9985-6684

Conselho de Ética em Pesquisa: (61) 3307-3709

Caso tenha entendido os procedimentos da pesquisa e deseje participar, favor assinar abaixo. Uma via deve ser mantida pelo responsável e a outra devolvida à escola para que seja repassada ao pesquisador.

Assinatura do Pai ou Responsável

Prof. ${ }^{a_{a}}$. Paula Ribeiro Mesquita 


\title{
Apêndice V - Termo de Assentimento
}

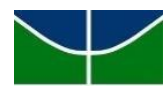

UnB

\author{
Programa de Mestrado em Educação Física - FEF \\ Campus Universitário Darcy Ribeiro - Asa Norte - Brasília-DF CEP: 70910-900
}

\section{Termo de Assentimento Livre e Esclarecido - TALE}

Você está sendo convidado a participar de uma pesquisa que está sendo feita para entender como acontece o crescimento e o desenvolvimento das crianças. O nome dessa pesquisa é Distribuição da Pressão Plantar durante o Andar e o Correr em Crianças e ela será feita pela professora Paula Ribeiro Mesquita.

Nesse trabalho queremos entender como as crianças andam e correm e como o seu pé funciona durante esses movimentos. Para isso, visitaremos a sua escola e, durante o horário normal de aulas, te convidaremos a realizar o teste. Nesse teste, você precisará andar e correr algumas vezes sobre um tapete que levaremos e que vai nos mostrar no computador como o seu pé funciona quando você anda ou corre. A sua participação é importante para que o crescimento das crianças seja estudado para melhorar a fabricação de tênis e sapatos infantis, por exemplo.

Você poderá tirar suas dúvidas com os professores a qualquer momento e a sua participação é voluntária e gratuita, ou seja, só irá participar quem quiser e não será necessário pagar para participar. Você também pode se recusar a responder ou participar de qualquer teste se não se sentir bem.

Obrigada.

Brasília, de de

Paula Ribeiro Mesquita

E-mail:paulamesquitaa@hotmail.com

Telefone: (061) 91636999 